\title{
LA INCLUSIÓN SOCIO-LABORAL DE LOS GRUPOS VULNERABLES. COLECTIVOS $Y$ FORMAS DE INCLUSIÓN A TRAVÉS DEL TRABAJ0
}

\author{
Aitor Bengoetxea Alkorta \\ Profesor Agregado de Derecho del Trabajo y de la Seguridad Social \\ Universidad del País Vasco / Euskal Herriko Unibertsitatea \\ Director de GEZKI \\ Grupo de Investigación "Economía Social, Autogestión y Empleo"1 \\ Grupo de Investigación del sistema universitario vasco IT1327-19, \\ "Gizarte Ekonomia eta bere Zuzenbidea"
}

\section{RESUMEN}

La noción de los grupos vulnerables se encuentra cada vez más extendida en la literatura sociológica, y también en la jurídica. Pero no hay un concepto jurídico-positivo sobre los mismos, ni una lista que los enumere con carácter exhaustivo. Se propone analizar el origen y contornos de esa noción, esbozando un concepto jurídico. En materia de acceso al empleo, la ley de empleo los denomina colectivos prioritarios. Estudiaremos cuáles son, por qué se les considera colectivo prioritario, en función de las peculiaridades de cada uno de ellos, y qué medidas de acción positiva se les aplican, partiendo de su desventaja, para procurar ayudarles en su esfuerzo hacia la consecución de un empleo.

PALABRAS CLAVE: Grupos vulnerables, colectivos prioritarios, acceso al empleo, acción positiva, inclusión laboral, inclusión social.

CLAVES ECONLIT: J14, J15, J16, J71, J78, K31.

Cómo citar este artículo/How to cite this article: BENGOETXEA ALKORTA, A.: “La inclusión socio-laboral de los grupos vulnerables. Colectivos y formas de inclusión a través del trabajo", CIRIEC-España, Revista Jurídica de Economía Social y Cooperativa, $\mathrm{n}^{0}$ 36, 2020, pp. 15-53. DOI: $10.7203 /$ CIRIEC-JUR.36.17247. 
(pp. 15-53)

\section{THE SOCIO-LABOR INCLUSION OF VULNERABLE GROUPS. GROUPS AND FORMS OF INCLUSION THROUGH WORK}

\section{EXPANDED ABSTRACT}

The present study deals with the subject of access to employment for vulnerable groups. The first challenge is to seek a correct approach to the concept of vulnerable groups. The question is complex, because there is no legal concept on these groups of people. In positive law, and in language in general, the expression vulnerable group is used with increasing profusion. In a legal analysis, the absence of a legal concept of vulnerability leads us to tackle the difficult task of seeking its delimitation, an issue that we will address in this article.

Nor does the law provide us with an exhaustive list that clearly indicates which are the vulnerable groups. If we compare different norms that deal with the issue, we can verify that these groups (women, people with disabilities, young people, elderly people, people in a situation of social exclusion, etc.) largely coincide. But there is no rule that defines us specifically, providing legal certainty, which are the vulnerable groups.

As a method to approach this concept, we will study the sociological notion of vulnerable groups, and the groups that compose them, and then approach their legislative treatment. Afterwards, always with humility, we will try an outline of the long-awaited legal concept of these groups.

When trying to promote the social inclusion of vulnerable groups, employment is the key tool for that inclusion, because it provides economic and psychosocial tools to the vulnerable person, giving them autonomy, which leads to social inclusion. There are some exceptions where employment is not the solution (such as people with autism spectrum disorder).

At this point, if we approach social inclusion from the specific aspect of employment, the employment law contains a list of what it calls priority groups, which contains eight (youth, women, long-term unemployed, people over 45 years, people with family responsibilities, people with disabilities, people in situations of social exclusion, and immigrants). We can affirm that the priority groups, from the prism of access to employment, are the labor law version of vulnerable groups.

Starting from the positive law enumeration that provides us with a sure handle, we will observe which are these eight groups, individually. We will see why each of these eight groups is disadvantaged in the race for access to employment. We will study what, in each case, are 
(pp. 15-53)

the specific difficulties they experience to get a job. As far as possible, we will try to provide data from labor market statistics, to empirically corroborate its disadvantage.

After identifying those eight groups that the employment law classifies as priorities, there are various regulations on employment that seek to balance this situation of disadvantage. The instrument to try to apply justice and solidarity, as a response to this disadvantageous situation, are positive action measures. This restorative legislative policy sinks its positive law foundation in the Constitution, when, in its art. 9.2, indicates that it is up to the public powers to promote the conditions so that the freedom and equality of the individual and of the groups in which it is integrated are real and effective; remove the obstacles that impede or hinder its fullness and facilitate the participation of all citizens in political, economic, cultural and social life. In what interests us, the matter is seeking equality for vulnerable groups, or priority groups, in access to employment.

Therefore, we will present the main positive action measures that the employment regulations establish for each of the eight priority groups. To do this, we will use a broad notion of employment, which we believe to be correct, encompassing all types of employment. In addition to the hegemonic employees in the private sector, we will study the positive action measures that exist to promote the employment of vulnerable groups in public employment; in self-employment (individual self-employment); and also in collective self-employment (worker cooperatives and labor companies).

To achieve the objectives of the study, a first objective would be to try to shed some light, from the labor law focus, on that elusive notion of vulnerable groups. Starting from the non-existence of a legal concept of vulnerable groups, we will try to delimit it from the normative and meta-legal instruments within our reach.

Subsequently, we will try to delve into the particular characteristics of each of the eight priority groups for access to employment, specific characteristics that, in short, justify their consideration as such priority groups or vulnerable groups.

Later, with a descriptive nature, we will present the positive action measures that we have found, aimed at promoting access to employment for each of these eight groups, leaving their evaluation for the conclusions.

As a methodological point, we want to indicate that we will study the particular discriminatory factors that affect each of the groups, without studying the phenomena of multiple discrimination. Of course, we are aware of the importance of analyzing multiple discrimination, and we also know that such intersectoral discrimination occurs frequently. The reason 
that we do not study them is twofold. On the one hand, we want to focus our effort on the peculiarities of each group, because when they are mentioned in positive law, it is not usually indicated why they are a discriminated group. The second reason is space. Addressing multiple discrimination would require a broader study, which would go beyond the contours of this that we present here.

Regarding the territorial scope, the generic study of vulnerable groups will analyze international and state regulations. In the matter of access to employment for priority groups, we will limit ourselves to state regulations, for reasons of space, without studying autonomous regulations, being aware of their importance, particularly with regard to positive action measures, where the variety in autonomous comparative law, and even in local law, is remarkable.

In terms of structure, the study begins with the concept of vulnerable groups. Next, the relationship between social inclusion and labor inclusion policies is analyzed. The following section is devoted to access to employment for vulnerable groups, dedicating a section to each of the eight priority groups. We will finish with the conclusions obtained.

KEYWORDS: Vulnerable groups, Priority groups, Access to employment, Positive action, Labor inclusion, Social inclusion 


\section{SUMARIO}

1. Introducción 2. Grupos vulnerables. 2.1. Origen de la noción de grupos vulnerables. 2.2. Referencias a grupos vulnerables en el derecho positivo. 2.3. ¿Se puede confeccionar un listado de grupos vulnerables? 2.4. El concepto jurídico de los grupos vulnerables. 3. Inclusión socio-laboral de los grupos vulnerables. 4. El acceso al empleo de los grupos vulnerables. 4.1. No discriminación en el acceso al empleo. 4.2. Los colectivos prioritarios. 4.3. Acción positiva en favor del acceso al empleo de los colectivos prioritarios. 5. Conclusiones. Bibliografía.

\section{Introducción}

El presente estudio gira en torno al acceso al empleo de los grupos vulnerables. Tema vidrioso, en primer lugar, por la inexistencia de concepto jurídico sobre los mismos. Tampoco existe una enumeración cerrada que nos indique con claridad cuáles son.

Procuraremos estudiar la noción sociológica de los grupos vulnerables, y los colectivos que los componen, para después aproximarnos a su tratamiento legislativo. También ensayaremos un esbozo del concepto jurídico de dichos grupos.

Si centramos la cuestión, partiendo de la inclusión social, hasta llegar al ámbito del acceso al empleo, el tema se clarifica, al menos en parte, porque la ley de empleo nos ofrece un catálogo de ocho colectivos prioritarios, versión jurídico-laboral de los grupos vulnerables. Así, observaremos cuáles son esos colectivos, y las dificultades adicionales que sufren para lograr un empleo, utilizando, en la medida de lo posible, las estadísticas del mercado de trabajo para corroborar su situación de desventaja. Después estudiaremos las medidas de acción positiva, para acceder al empleo, que tienen como destinatarias a las personas integrantes de esos colectivos.

El objetivo del estudio es procurar arrojar algo de luz, desde el foco iuslaboralista, a esa noción tan escurridiza de los grupos vulnerables. Posteriormente, se intentará ahondar en las características particulares de cada uno de los colectivos prioritarios para el acceso al empleo, que justifican su consideración como tales. Después veremos las medidas de acción positiva dirigidas a cada uno de ellos, dejando la valoración de las mismas para las conclusiones.

Desde la perspectiva metodológica, se estudiarán los factores discriminatorios particulares que afectan a cada uno de los colectivos, sin estudiar los fenómenos de 
discriminación múltiple. Siendo consciente de la importancia, y frecuencia, de esas discriminaciones intersectoriales, no serán estudiadas, para intentar concentrar los esfuerzos en las peculiaridades de cada colectivo.

En lo que respecta al ámbito territorial, en el estudio genérico de los grupos vulnerables se analizará la normativa internacional, y también estatal. En la materia del acceso al empleo de los colectivos prioritarios, nos limitaremos a la normativa estatal, por cuestiones de espacio, sin estudiar la normativa autonómica, siendo conscientes de su importancia, particularmente en lo que respecta a las medidas de acción positiva.

El estudio comienza con el concepto de los grupos vulnerables. Seguidamente, la relación entre las políticas de inclusión social y de inclusión laboral. El siguiente apartado se dedica al acceso al empleo de los grupos vulnerables, para terminar con las conclusiones obtenidas.

\section{Grupos vulnerables}

En el presente estudio sobre la inclusión sociolaboral de los grupos vulnerables, parece oportuno comenzar por procurar identificar los mismos. La aproximación desde el prisma del derecho positivo nos lleva directamente a la primera afirmación, no muy alentadora, de que no existe un concepto jurídico sobre los grupos vulnerables ${ }^{2}$. Por consiguiente, la noción nos coloca ab initio en el escenario de la inseguridad jurídica ${ }^{3}$.

$\mathrm{Si}$ acudimos, siguiendo la ortodoxia lingüística, al diccionario de la RAE, obtenemos como respuesta que vulnerable significa que puede ser herido o recibir lesión, física o moralmente. No parece satisfactoria la respuesta, en nuestra búsqueda de noción jurídica, porque, sin duda, toda la humanidad, potencialmente, es susceptible de ser herida o resultar lesionada, física o moralmente. Por eso, resulta muy atinada, y gráfica, la respuesta de un juez del Tribunal Europeo de Derechos Humanos (TEDH), a la pregunta sobre la configuración de la noción grupos vulnerables en la jurisprudencia del TEDH, cuando afirma, refiriéndose a los demandantes de amparo ante dicho tribunal, que todos son vulnerables, pero algunos son más vulnerables que otros ${ }^{4}$.

2. Destacando esa circunstancia, FERNÁNDEZ VILLAZÓN, L.A.: "Grupos vulnerables: apuntes para un concepto jurídico-social”, Estudios Financieros-Revista de Trabajo y Seguridad Social, no 404, 2016, p. 112; MINAARRO YANINI, M.: "La protección socio-laboral de los refugiados como grupo vulnerable: balance crítico y propuestas de mejora”, Nueva revista española de derecho del trabajo, no 203, 2017, p. 3.

3. Como se ha afirmado con claridad, "la noción ha sido importada desde la sociología al derecho, pero sin haber elaborado simultáneamente una definición jurídica de la misma”, Miñarro Yanini, M., op. cit., p. 3.

4. "All applicants are vulnerable, but some are more vulnerable than others" fue la respuesta, en la interesante investigación de PERONI, L. \& TIMMER A.: "Vulnerable groups: The promise of an emerging concept in 
(pp. 15-53)

\subsection{Origen de la noción de grupos vulnerables}

Sin duda, la génesis de la noción de grupos vulnerables se encuentra en la normativa internacional de los derechos humanos, en torno a la expresión vulnerable groups.

Tras las declaraciones de derechos humanos de ámbito universal, cuando se pone el foco en el aspecto de esa universalidad, afloran los grupos vulnerables, colectivos de personas con dificultades específicas, derivadas de sus características grupales, para ejercer esos derechos a los que se ha dotado de ámbito subjetivo de aplicación universal.

A partir de ahí, resulta imprescindible atender las necesidades específicas de esos grupos por motivos de igualdad ${ }^{6}$. No es suficiente con que todas las personas sean titulares de derechos humanos universales, se requiere asimismo que puedan ejercerlos en condiciones de igualdad ${ }^{7}$.

Para lograr que esa universalidad sea real, y no solo nominal, se requiere identificar esos grupos con características propias de desventaja, y, a continuación, adoptar medidas para lograr que las personas integradas en ellos gocen de sus derechos universales al igual que lo hacen las personas no incluidas en dichos colectivos.

Para comenzar a perfilar las características que determinan la consideración de determinado grupo como vulnerable, en el ámbito del derecho internacional humanitario, hay que destacar la labor de la Organización Internacional del Trabajo (OIT), y, más aún, del TEDH.

Así, en lo que respecta a la OIT, en el preámbulo de su propio texto fundacional de 1919, en el ámbito de los derechos humanos laborales universales, se refiere a la protección de los niños, de los adolescentes y de las mujeres, a las pensiones de vejez y de invalidez, y protección de los intereses de los trabajadores ocupados en el extranjero. Aunque no se utiliza todavía la expresión grupos vulnerables, cabe colegir, sin mayor esfuerzo, que se está refiriendo a los principales que observaba en su contexto

European Human Rights Convention law”, International Journal of Constitutional Law, vol. 11, n 4, 2013 , pp. 1060-1061.

5. En ese sentido, Fernández Villazón, L. A. (2016), op. cit., p. 114.

6. De esa manera, "en el llamado proceso de especificación de los derechos humanos se han ido concretado normas específicas de protección de los derechos de distintos grupos humanos", TRINIDAD NÚNEZZ, P.: "La evolución en la protección de la vulnerabilidad por el Derecho Internacional de los Derechos Humanos", Revista Española de Relaciones Internacionales, n 4, 2012, p. 127.

7. "Es la dignidad como seres humanos de esas personas lo que está en riesgo y, por lo tanto, la vulnerabilidad de la que hablamos se concreta en obstáculos específicos para el ejercicio de los derechos humanos", Fernández Villazón, L.A. (2016), op. cit., p. 114. 
histórico. Posteriormente, como veremos, esa previsión genérica se ha desarrollado en varios Convenios de la propia OIT.

De gran interés resulta la labor creativa del TEDH. En el mismo sentido que la OIT, ha sido su vocación de garantizar la universalidad real lo que le ha llevado a prestar atención específica a la situación de los grupos vulnerables ${ }^{8}$.

Se puede sintetizar la noción de grupo vulnerable elaborada por el TEDH en torno a tres factores: carácter relativo, situación particular, y lesión sufrida?

El carácter relativo significa que la condición de grupo vulnerable se adquiere no por mostrar determinadas características per se, sino cuando ponemos esas características en relación con el entorno social del grupo. En ese momento salen a relucir factores sociales e históricos que llevan a delimitar al grupo como colectivo con características sociales específicas. A menudo, discriminación con respecto al resto de la sociedad.

El elemento de la situación particular pone de relieve el hecho de que estamos ante un grupo cuya vulnerabilidad está determinada por experiencias específicas colectivas, que el grupo como tal ha conocido y conoce. Por ejemplo, racismo.

El tercer y último elemento es el de la lesión sufrida. En este caso, se pueden distinguir dos aspectos. Por una parte, falta de reconocimiento (misrecognition) derivada de los prejuicios y de la estigmatización que sufre el grupo vulnerable en cuestión. Por ejemplo, gitanos. El otro aspecto es el de la distribución inequitativa (maldistribution), que produce desventaja social y privación material ${ }^{10}$. Circunstancias que pueden derivar, evidentemente, en pobreza y exclusión social.

\subsection{Referencias a grupos vulnerables en el derecho positivo}

En la normativa internacional de derechos humanos no solía aparecer literalmente la expresión grupos vulnerables, pero hay muchas normas internacionales promulgadas para proteger a personas integradas en varios de ellos. El último Convenio de

8. "Human rights law, however, has not always responded adequately to these particular vulnerabilities given the import of the liberal legal subject into its structure and the exclusion of those who do not fit the liberal archetype. We have argued that it is in response to these exclusions of human rights law that the Court has been forced to attend to the constructed disadvantage of certain groups. In doing so, the Court has deployed the concept of group vulnerability. In this light, we see the Court's reasoning as a way of opening up the human rights universal, as a step towards a more inclusive universal human rights subject", Peroni, L., Timmer A., op. cit., p. 1085.

9. Sigo en este punto a Peroni, L., Timmer A., op. cit., pp. 1065-1065.

10. Los referidos autores toman los conceptos de misrecognition y maldistribution de FRASER, N.: "Rethinking Recognition”, 3 New Left Review, 107, 113, 2000. 
(pp. 15-53)

la OIT (2019), sí que se refiere literalmente a los grupos vulnerables, aunque sin aportar su concepto, ni indicar cuáles son ${ }^{11}$.

Tempranamente, en el año 1919, en el que se constituyó la OIT, fueron promulgadas normas para proteger a las mujeres ${ }^{12}$ y la infancia ${ }^{13}$. Esos dos colectivos fueron los primeros en recibir la protección jurídica internacional, señalando el camino para la tutela de otros grupos vulnerables ${ }^{14}$. Posteriormente, esos dos grupos han sido objeto de varios tratados de la propia $\mathrm{OIT}^{15}$. Con un criterio más amplio, el Convenio 111 OIT prohíbe la discriminación por motivos de raza, color, sexo, religión, opinión política, ascendencia nacional u origen social ${ }^{16}$. Como veremos infra, la temática de los grupos vulnerables se encuentra estrechamente relacionada con el principio de no discriminación.

Más allá de la OIT, en la esfera internacional de la ONU se han aprobado varios tratados internacionales dirigidos a la protección de diversos grupos vulnerables. Podemos destacar, siguiendo un orden cronológico, los supuestos de los refugiados ${ }^{17}$, raza $^{18}$, mujeres $^{19}$, infancia ${ }^{20}$, migrantes ${ }^{21}$, o personas con discapacidad ${ }^{22}$.

11. Convenio no 190 OIT, sobre la violencia y el acoso (1919). Su art. 7 establece que "todo Miembro deberá adoptar una legislación y políticas que garanticen el derecho a la igualdad y a la no discriminación en el empleo y la ocupación, incluyendo a las trabajadoras, así como a los trabajadores y otras personas pertenecientes a uno o a varios grupos vulnerables, o a grupos en situación de vulnerabilidad que están afectados de manera desproporcionada por la violencia y el acoso en el mundo del trabajo".

12. Convenio no 3 OIT, sobre la protección de la maternidad (1919); Convenio no 4 OIT, sobre el trabajo nocturno de las mujeres (1919).

13. Convenio no 5 OIT, sobre la edad mínima en la industria (1919); Convenio no 6 OIT, sobre el trabajo nocturno de los menores en la industria (1919).

14. Destacando esa circunstancia, Trinidad Núñez, P., op. cit., p. 129.

15. Como el Convenio no 100 OIT, sobre igualdad de remuneración (1951), del que cabe destacar que, en esa lejana fecha, ya estableció la igualdad de remuneración entre la mano de obra masculina y la mano de obra femenina por un trabajo de igual valor; o el Convenio $n^{\circ} 182$ OIT, sobre las peores formas de trabajo infantil (1999).

16. Convenio no 111 OIT, sobre la discriminación en el empleo y la ocupación (1958).

17. Convención sobre el estatuto de los refugiados (1951).

18. Convenio internacional sobre eliminación de todas las formas de discriminación racial (1965).

19. Convención sobre la eliminación de todas las formas de discriminación contra la mujer (1979).

20. Convención sobre los derechos del niño (1989).

21. Convención internacional sobre la protección de los derechos de todos los trabajadores migratorios y de sus familiares (1990).

22. Convención internacional de derechos de las personas con discapacidad (2006). 
Como conclusión sobre la normativa internacional de los derechos humanos, podemos afirmar que hay que reconocerle su carácter pionero en el lanzamiento de la noción de grupos vulnerables, sin que haya llegado a culminar su obra con la elaboración de su concepto jurídico, que los juristas anhelamos.

La Unión Europea, como es sabido, no nació precisamente para tutelar los derechos de los más vulnerables, ni de los menos vulnerables, sino para crear un mercado único europeo, con un ánimo liberal y economicista. Sin embargo, durante su evolución histórica ha ido incorporando, y sigue haciéndolo, preceptos que proclaman derechos humanos, refiriéndose específicamente, en ocasiones, a su disfrute por parte de personas integradas en grupos vulnerables ${ }^{23}$.

En el derecho originario, tras algunos avances por parte del Tratado de la Unión Europea (TUE) ${ }^{24}$ y del Tratado de Funcionamiento de la Unión Europea (TFUE) ${ }^{25}$, sin duda la principal aportación en materia de protección de grupos vulnerables la realiza la Carta de Derechos Fundamentales de la Unión Europea (CDFUE), cuando prohíbe las discriminaciones por razón de sexo, raza, color, orígenes étnicos o sociales, características genéticas, lengua, religión o convicciones, opiniones politicas o de cualquier otro tipo, pertenencia a una minoria nacional, patrimonio, nacimiento, discapacidad, edad u orientación sexual (art. 21) ${ }^{26}$. Además, la CDFUE presta atención a los de-

23. Destacando la notable influencia de la OIT sobre posteriores pronunciamientos de la Unión Europea, FERNÁNDEZ VILLAZÓN, L.A.: "La OIT y los grupos vulnerables. Especial atención a la vulnerabilidad de género y a la protección de la infancia", Estudios Financieros-Revista de Trabajo y Seguridad Social, no 434, 2019 , p. 123.

24. La Unión se fundamenta en los valores de... respeto de los derechos humanos, incluidos los derechos de las personas pertenecientes a minorias (art. 2); la Unión combatirá la exclusión social y la discriminación y fomentará... la igualdad entre mujeres y hombres, la solidaridad entre las generaciones y la protección de los derechos del niño (art. 3).

25. En la definición y ejecución de sus politicas y acciones, la Unión tratará de luchar contra toda discriminación por razón de sexo, raza u origen étnico, religión o convicciones, discapacidad, edad u orientación sexual (art. 10); entre las materias sobre las que la UE apoyará la acción de los Estados miembros se encuentran las condiciones de empleo de los nacionales de terceros paises, la lucha contra la exclusión social y la igualdad entre hombres y mujeres.

26. Posteriormente, esa previsión ha sido desarrollada mediante la Directiva 2000/43/CE del Consejo, de 29 de junio de 2000, relativa a la aplicación del principio de igualdad de trato de las personas independientemente de su origen racial o étnico; Directiva 2000/78/CE del Consejo, de 27 de noviembre de 2000, relativa al establecimiento de un marco general para la igualdad de trato en el empleo y la ocupación; y la Directiva 2006/54/CE del Parlamento europeo y del Consejo de 5 de julio de 2006, relativa a la aplicación del principio de igualdad de oportunidades e igualdad de trato entre hombres y mujeres en asuntos de empleo y ocupación (refundición). 
(pp. 15-53)

rechos específicos de algunos grupos vulnerables, como los refugiados ${ }^{27}$, mujeres ${ }^{28}$, menores $^{29}$, mayores ${ }^{30}$, y personas con discapacidad ${ }^{31}$.

En el derecho derivado europeo, es posible incluso encontrar referencias literales a los grupos vulnerables ${ }^{32}$. De gran interés resulta el catálogo que ofrece la Directiva 2011/95/UE, cuando se refiere a la situación especifica de personas vulnerables como los menores, los menores no acompañados, las personas discapacitadas, los ancianos, las mujeres embarazadas, los padres solos con hijos menores, las victimas de trata de seres humanos, las personas con trastornos psiquicos y las personas que hayan padecido tortura, violación $u$ otras formas graves de violencia psicológica, física o sexua ${ }^{3}$.

En cualquier caso, y aún reconociendo las aportaciones del derecho europeo al desarrollo de la noción de los grupos vulnerables, especialmente en la definición de personas vulnerables que acabamos de ver, no existe en el mismo un concepto jurídico de grupos vulnerables, ni de personas vulnerables ${ }^{34}$.

En lo que respecta al derecho positivo español, el rastreo en busca de los grupos vulnerables nos arroja como resultado la existencia de varias menciones aisladas, lejos de la configuración de un concepto jurídico sobre los mencionados colectivos ${ }^{35}$.

\section{Art. 18 CDFUE.}

\section{Art. 23 CDFUE.}

\section{Art. 24 CDFUE.}

30. Art. 25 CDFUE.

\section{Art. 26 CDFUE.}

32. Así sucede, por ejemplo, en el Reglamento (UE) 233/2014 del Parlamento europeo y del Consejo de 1 de marzo de 2014, por el que se establece un Instrumento de Financiación de la Cooperación al Desarrollo para el período 2014-2020; y en el Reglamento (UE) 1303/2003 del Parlamento europeo y del Consejo de 17 de diciembre de 2013, por el que se establecen disposiciones comunes relativas al Fondo Europeo de Desarrollo Regional, al Fondo Social Europeo, al Fondo de Cohesión, al Fondo Europeo Agrícola de Desarrollo Rural y al Fondo Europeo Marítimo y de la Pesca.

33. Art. 20.3 de la Directiva 2011/95/UE del Parlamento europeo y del Consejo, de 13 de diciembre de 2011, por la que se establecen normas relativas a los requisitos para el reconocimiento de nacionales de terceros países o apátridas como beneficiarios de protección internacional, a un estatuto uniforme para los refugiados o para las personas con derecho a protección subsidiaria y al contenido de la protección concedida.

34. En ese sentido, coincidimos con la reflexión de que "no se ha producido en el ámbito del Derecho Europeo una asimilación de la idea de grupos vulnerables por parte de las normas jurídicas. Estas siguen tomando como base la conceptuación empleada en el ámbito de las políticas. Podemos así concluir que, por el momento, el de grupos vulnerables no es un concepto propiamente jurídico, sino una idea previa que inspira la acción del legislador comunitario", Fernández Villazón, L.A. (2016), op. cit., p. 122.

35. En la misma línea, Fernández Villazón, L.A. (2016), op. cit., p. 131. 
(pp. 15-53)

Así, podemos mencionar varios ejemplos. La Ley de cooperación al desarrollo se refiere a los grupos de población más vulnerables (menores, con especial atención a la erradicación de la explotación laboral infantil, refugiados, desplazados, retornados, indigenas, minorias $)^{36}$. La Ley del tercer sector de acción social establece una interesante conexión entre grupos vulnerables y exclusión social, llegando a referirse a grupos vulnerables en riesgo de exclusión socia ${ }^{37}$, como si fueran partes integrantes del mismo concepto.

Tal y como ha sido destacado ${ }^{38}$, en otros ámbitos más allá del terreno sociolaboral, también hay interesantes referencias jurídico positivas a víctimas vulnerables y personas especialmente vulnerables, en el ámbito penal ${ }^{39}$, que liga esa situación a los factores de la edad, enfermedad, estado gestacional, discapacidad, y minoría de edad. En el ámbito de las personas deudoras, también podemos encontrar menciones a los colectivos especialmente vulnerables, en función de la edad o situación familiar ${ }^{40}$. También en la legislación de personas consumidoras y usuarias se identifica la figura del consumidor vulnerable $e^{41}$, en función de sus responsabilidades familiares y nivel de renta.

\section{3. ¿ Se puede confeccionar un listado de grupos vulnerables?}

Partimos de la certeza de que no existe una lista cerrada de grupos vulnerables, en el ordenamiento jurídico globalmente considerado ${ }^{42}$. A partir de ahí, y dando por sentado que no va a ser exhaustiva, como agregado de los colectivos mencionados supra, y añadiéndole otros que aparecen no en normas jurídico-positivas sino en

36. Art. 7 de la Ley 23/1998, de 7 de julio, de cooperación internacional para el desarrollo.

37. Art. 7 f) de la Ley 43/2015, de 9 de octubre, del Tercer Sector de Acción Social. Si bien es cierto que, cuando establece el concepto de Las entidades del Tercer Sector de Acción Social, el art. 2 de dicha ley se refiere a grupos que sufren condiciones de vulnerabilidad o que se encuentran en riesgo de exclusión social, pareciendo referirse a situaciones distintas.

38. Interesante estudio de Miñarro Yanini, M., op. cit., p. 4.

39. Expresiones utilizadas en el Código Penal, Ley Orgánica 10/1995, de 23 de noviembre.

40. Art. 1.2 de la Ley 1/2013, de 14 de mayo, de medidas para reforzar la protección a los deudores hipotecarios, reestructuración de deuda y alquiler social.

41. Art. 3 del Real Decreto 897/2017, de 6 de octubre, por el que se regula la figura del consumidor vulnerable, el bono social y otras medidas de protección para los consumidores domésticos de energía eléctrica. En el art. 4 define, como categoría específica, al consumidor en riesgo de exclusión social.

42. En el mismo sentido, Trinidad Núné, P., op. cit., p. 128. 
(pp. 15-53)

algún documento soft law $w^{43}$, podríamos ensayar la elaboración de la siguiente lista de factores de vulnerabilidad:

Sexo, raza, color, orígenes étnicos o sociales, características genéticas, lengua, religión o convicciones, opiniones políticas o de cualquier otro tipo, pertenencia a una minoría nacional, patrimonio, nacimiento, discapacidad, edad (mayores, jóvenes, y menores), orientación sexual, migrantes, refugiados, madres o padres solos con hijos menores, las víctimas de trata de seres humanos, las personas con trastornos psíquicos y las personas que hayan padecido tortura, violación u otras formas graves de violencia psicológica, física o sexual, nivel de renta, responsabilidades familiares, personas sin hogar, personas con problemas de adicción, personas reclusas o exreclusas, parados de larga duración, menores tutelados, jóvenes extutelados, personas en situación de dependencia, y personas con infección por el VIH.

Desde luego, no se trata de una lista cerrada. La cuestión de interés sería, desde la perspectiva de la seguridad jurídica, ¿conviene que haya lista cerrada? Creemos que no.

Los factores de vulnerabilidad son, per se, cambiantes, en función de las circunstancias socioeconómicas de cada territorio y período histórico. Las sociedades, sus valores, y sus variables socioeconómicas evolucionan constantemente. Por eso, la pretensión de lista cerrada no sólo sería estéril, sino también contraproducente. Siempre podría haber grupos que quedaran fuera de esa lista.

Por consiguiente, podemos concluir este punto afirmando que no existe lista cerrada de grupos vulnerables, ni en derecho internacional ni en derecho interno, y es mejor que no la haya ${ }^{44}$. Una lista cerrada, pretendiendo seguridad jurídica, tendría el efecto pernicioso de no considerar grupos vulnerables a colectivos merecedores de esa calificación.

Lo que sí sería deseable es un concepto jurídico omnicomprensivo de la categoría de los grupos vulnerables. En el imaginario colectivo ya existe una idea, más o menos clara, de lo que son grupos vulnerables. Pero eso no es suficiente para el operador jurídico, que necesita delimitar con claridad el supuesto de hecho de los grupos

43. Estrategia Nacional de Prevención y Lucha contra la Pobreza y la Exclusión Social (2019-2023).

44. "La idea de vulnerabilidad se concibe como un concepto vivo que se adapta constantemente a las circunstancias sociales y económicas. Tal es la idea que barajan las instituciones internacionales y europeas, pues lo que estas consideran vulnerable está sujeto a revisión en cada momento", Fernández Villazón, L.A. (2016), op. cit., p. 133; "se trata de un sector en pleno desarrollo, tanto desde el punto de vista de los grupos protegidos, ya que no se trata de una lista cerrada, como de la determinación del contenido y alcance de los derechos de los mismos. Pero esta situación inacabada, no puede verse como algo negativo, ya que no es sino la expresión misma del propio proceso de formación del Ordenamiento jurídico internacional”, Trinidad Núnez, P., op. cit., p. 162. 
vulnerables, para poder anudar las correspondientes consecuencias jurídicas. Es la seguridad jurídica lo que está en juego.

\subsection{El concepto jurídico de los grupos vulnerables}

Empecemos por el término más fácil de abordar, el de grupos. Podemos asimilar la noción de grupo a la de colectivo, y de esa manera llegamos a un concepto muy arraigado en el derecho del trabajo.

Así, dentro de la ciencia del derecho del trabajo es clásica la distinción entre derecho individual y derecho colectivo. El derecho individual del trabajo gira en torno a la relación laboral tejida entre la persona trabajadora y la empleadora, que se juridifica en el contrato de trabajo. Mientras tanto, la dimensión colectiva del derecho del trabajo tiene como objeto los intereses colectivos de determinado grupo de personas, trabajadoras o empleadoras.

El interés colectivo es indivisible entre los miembros del grupo, de manera que hay una característica común que le otorga, precisamente, la categoría grupal o colectiva. Por ejemplo, personas trabajadoras del turno de mañana, con contrato temporal, mujeres trabajadoras de una empresa, etc. Así, las personas pertenecientes a determinado grupo tienen un interés colectivo, en común, que se deriva de su propia pertenencia a ese colectivo. Una vez definido ese interés colectivo, como supuesto de hecho, el derecho del trabajo arbitra instrumentos jurídicos para canalizar su defensa, como los sujetos colectivos (sindicatos, asociaciones empresariales), o los instrumentos de acción colectiva (negociación colectiva, huelga).

Esa doctrina emanada del derecho del trabajo es perfectamente extrapolable a la expresión grupo, en el contexto de los grupos vulnerables. Así, las personas integrantes de determinado grupo vulnerable tienen una característica común, un factor de vulnerabilidad que comparten (sexo, edad, raza, religión, etc.), y las ubica dentro de la categoría de ese grupo. Es una circunstancia individual y grupal, de manera simultánea.

Más compleja de abordar resulta, desde luego, la expresión vulnerable. Hemos visto supra la construcción jurídica del TEDH, que hace girar la vulnerabilidad sobre los elementos de carácter relativo, situación particular, y lesión sufrida. Podemos destacar también alguna aproximación doctrinal de interés.

Así, hay quien pone el acento en las "dificultades sociales, económicas y jurídicas que impiden el adecuado desarrollo de su personalidad" ${ }^{45}$. También se ha ensayado la 
(pp. 15-53)

construcción del concepto de grupos vulnerables haciéndolo descansar sobre cuatro rasgos definitorios: carácter colectivo; desventaja social; impacto negativo socio-económico que provoca riesgo de exclusión; y reversibilidad del factor de vulnerabili$\mathrm{dad}^{46}$.

La cuestión no es fácil. Las distintas aportaciones arrojan luz para configurar la noción, pero delimitar el concepto jurídico de los grupos vulnerables es ciertamente una tarea compleja.

La aproximación que me parece más acertada es la que liga grupos vulnerables con exclusión social ${ }^{47}$. Cuando hablamos de vulnerabilidad, hablamos de vulnerabilidad social ${ }^{48}$, haciendo referencia a grupos de personas que se encuentran excluidas de la sociedad, por no poder ejercer sus derechos humanos en igualdad de condiciones con respecto a las personas socialmente incluidas; o a grupos de personas en riesgo de caer en esa exclusión social.

Así, los grupos vulnerables serían aquellos integrados por personas en situación o riesgo de exclusión social, debido a la presencia de algún factor, o varios factores, de vulnerabilidad. En el primer caso, la vulnerabilidad ya se ha materializado, y es un grupo con derechos vulnerados ${ }^{49}$; el segundo sería, propiamente, el grupo vulnerable, en el sentido de que tiene riesgo cierto de que sus derechos sean vulnerados.

estarlo; esa especial situación de desprotección exige que se desplieguen mecanismos específicos de protección; es necesario que la condición de vulnerable sea reconocida por el ordenamiento jurídico", Fernández Villazón, L.A. (2019), op. cit., p. 127. El autor ańade, en el mismo lugar, que "la vulnerabilidad se concreta, además, en dos dimensiones o realidades, dependiendo del tipo de intereses o bienes jurídicos que se encuentren en riesgo. Por un lado, lo que está en juego en primer término es la dignidad de los componentes del grupo como personas, es decir, sus derechos humanos. En esta dimensión es donde el concepto enlaza con la protección de los derechos fundamentales y la no discriminación. Por otra parte, la condición de vulnerable también puede proceder de la falta de recursos económicos. Ello la conecta con las ideas de pobreza y exclusión social".

46. Mińarro Yanini, M., op. cit., p. 5.

47. En el mismo sentido, la Estrategia Nacional de Prevención y Lucha contra la Pobreza y la Exclusión Social (2019-2023), se refiere "a las personas más vulnerables en situación de pobreza o exclusión social". También, poniendo en relación ambos conceptos, Ley 43/2015, de 9 de octubre, del Tercer Sector de Acción Social, como hemos visto supra; exposición de motivos de la Ley 44/2007, de 13 de diciembre, para la regulación del régimen de las empresas de inserción; Fernández Villazón, L.A. (2016), op. cit., p. 130, destaca la "íntima relación" entre el concepto de grupos vulnerables y el de personas en riesgo de exclusión.

48. Fernández Villazón, L.A. (2016), op. cit., p. 112.

49. Ibíd, p. 117. 
Entendiendo que necesitan protección tanto las personas en situación como en riesgo de exclusión social, creo que el concepto de grupos vulnerables debe comprender ambas situaciones ${ }^{50}$.

Así, en esa noción se podrían acomodar, implícitamente, los aspectos analizados, como los propuestos por el TEDH (carácter relativo, situación particular, y lesión sufrida); y por la doctrina científica (dificultades sociales, económicas y jurídicas que impiden el adecuado desarrollo de su personalidad, carácter colectivo, desventaja social, impacto negativo socio-económico que provoca riesgo de exclusión, y reversibilidad del factor de vulnerabilidad).

Desde luego, definir los grupos vulnerables como los integrados por personas en situación o riesgo de exclusión social lleva a demandar mayor concreción sobre el concepto de personas en exclusión social. La ley de empresas de inserción no las define, aunque sí aporta un listado de las mismas, a los efectos de la propia ley ${ }^{51}$.

En cualquier caso, para superar definitivamente la actual inseguridad jurídica con respecto al concepto de grupos vulnerables, la única solución sería que el legislador aborde esa difícil tarea. Ya que la idea nació en el ámbito del derecho internacional humanitario, lo más adecuado parece que el concepto jurídico de grupo vulnerable se elabore en ese mismo terreno, en el seno de la ONU. Aunque también sería jurídicamente eficaz la definición jurídico-positiva en derecho interno, aplicable en el correspondiente ámbito territorial.

En definitiva, más allá de los debates y matices sobre el concepto jurídico de los grupos vulnerables, hay unanimidad en la premisa de que son acreedores de pro-

50. Por el contrario, defendiendo que "el concepto jurídico de "grupos vulnerables» sólo puede incluir colectivos en «situaciones de riesgo", puesto que el objetivo de las normas es precisamente eliminar ese riesgo, neutralizando con ello la situación de desventaja", Miñarro Yanini, M., op. cit., p. 6. Coincidimos con la reflexión de que la idea de exclusión social tiende a verse cada vez menos una situación estática y más como un proceso, un continuum que va desde la integración a la exclusión y en el que la franja intermedia, la llamada «zona de vulnerabilidad» es cada vez más grande, Fernández Villazón, L.A. (2016), op. cit., p. 116.

51. Art. 2 de la Ley 44/2007, de 13 de diciembre, para la regulación del régimen de las empresas de inserción considera personas en situación de exclusión social a las que estén incluidas en alguno de estos colectivos: a) Perceptores de Rentas Minimas de Inserción, o cualquier otra prestación de igual o similar naturaleza, según la denominación adoptada en cada Comunidad Autónoma, así como los miembros de la unidad de convivencia beneficiarios de ellas; b) Personas que no puedan acceder a las prestaciones a las que se hace referencia en el párrafo anterior, por alguna de las siguientes causas: $1 .{ }^{\circ}$ Falta del periodo exigido de residencia o empadronamiento, o para la constitución de la Unidad Perceptora. 2. ${ }^{\circ}$ Haber agotado el periodo máximo de percepción legalmente establecido. c) Jóvenes mayores de dieciocho años y menores de treinta, procedentes de Instituciones de Protección de Menores; d) Personas con problemas de drogodependencia u otros trastornos adictivos que se encuentren en proceso de rehabilitación o reinserción social; e) Internos de centros penitenciarios, asi como liberados condicionales y ex reclusos; $f$ ) Menores internos, asi como los que se encuentran en situación de libertad vigilada y los ex internos; g) Personas procedentes de centros de alojamiento alternativo; h) Personas procedentes de servicios de prevención e inserción social. 
(pp. 15-53)

tección jurídica específica, para lograr su inclusión social (personas en situación de exclusión social); o su no exclusión social (personas en riesgo de exclusión social).

En el siguiente apartado trataremos esa cuestión de la inclusión social, centrándonos en el aspecto de la inclusión laboral.

\section{Inclusión socio-laboral de los grupos vulnerables}

En el apartado anterior hemos ensayado la definición de los grupos vulnerables como aquellos que se encuentran en situación o riesgo de exclusión social. En este apartado, trataremos la cuestión del esfuerzo que se realiza para la inclusión socio-laboral de dichos grupos, procurando de esa manera evitar su exclusión social ${ }^{52}$.

Cuando hablamos de inclusión socio-laboral, nos referimos a la inclusión en la sociedad y, en el aspecto laboral, al acceso al empleo. Así, el planteamiento consiste en la inclusión en la sociedad a través del trabajo de los grupos vulnerables, por encontrarse en situación de exclusión social, o por encontrarse en el límite, esto es, en riesgo de exclusión social.

Como objeto sobre el que interviene la inclusión socio-laboral, pasemos a observar las expresiones exclusión social y exclusión laboral. La exclusión social hace referencia a la circunstancia que sufren los grupos que se hallan, en sentido figurado, fuera de la sociedad, porque no pueden ejercer en la misma sus derechos humanos fundamentales (sociales, económicos, culturales), en igualdad de condiciones con los demás. La idea de exclusión laboral parece más simple, se trata de no tener empleo.

Si ponemos en relación ambas locuciones, podemos afirmar que, a menudo, la exclusión social conlleva exclusión laboral. La situación de exclusión social, en sí misma, supone un obstáculo para acceder al empleo. Esa relación parece evidenciarse cuando la ley de empresas de inserción se refiere a "personas en situación de exclusión social desempleadas e inscritas en los servicios públicos de empleo, con especiales dificultades para su integración en el mercado de trabajo" ${ }^{33}$, de manera que es la exclusión social la que produce especiales dificultades para lograr empleo. La exclusión social a menudo produce prejuicios y estigmatizaciones, además de eventuales déficits formativos, que dificultan la contratación de las personas en esa situación.

52. La Estrategia Nacional de Prevención y Lucha contra la Pobreza y la Exclusión Social (2019-2023) se fija como objetivo "la inclusión social plena de las personas más vulnerables". Si vamos al origen de la vulnerabilidad, "para que una traba social determine la consideración de un grupo como vulnerable es preciso que produzca la imposibilidad de integración socio-laboral del grupo en condiciones de igualdad con el resto de la sociedad", Mińarro Yanini, M., op. cit., p. 5.

53. Art. 2 de la Ley 44/2007, de 13 de diciembre, para la regulación del régimen de las empresas de inserción. 
También podemos reiterar la afirmación invirtiendo el orden de ambas expresiones. A menudo, la exclusión laboral conlleva exclusión social. La situación de no empleo, tanto en el caso de personas inactivas que no lo buscan, como de personas desempleadas que lo demandan pero no lo logran, frecuentemente coloca a esas personas en situación vulnerable desde la perspectiva económica, psicológica (autoestima, sentido de pertenencia), y social. Para soportar empíricamente esa afirmación, podemos traer a colación que desde instancias oficiales se aporta el dato de que "el riesgo de pobreza entre la población desempleada es 5 veces superior que entre la población ocupada" 54 .

Llegados a este punto, si la exclusión social a menudo provoca exclusión laboral, y viceversa, esa dinámica puede llevar a las personas vulnerables a un círculo vicioso del que no pueden escapar. Para romper ese círculo, la herramienta más eficaz es el empleo. Normalmente, la inclusión laboral conlleva inclusión social ${ }^{55}$. El empleo proporciona factores económicos y psicosociales a la persona vulnerable, dotándole de autonomía, que le catapulta hacia la inclusión social ${ }^{56}$.

Siendo cierto que el empleo es la principal llave para la inclusión social, no siempre resulta eficaz. Así, cuando las condiciones de trabajo son muy precarias, se pro-

54. Estrategia española de activación para el empleo 2017-2020, presentación resumen en power-point editada por el Ministerio de empleo y seguridad social, p. 5.

55. Idea sobre la que se insiste desde diversos ámbitos. Así, podemos leer que "la presente Estrategia pone el acento en la necesidad de desarrollar políticas de empleo inclusivas que tengan como objetivo que las personas más vulnerables logren un empleo de calidad, que les permita vivir en unas condiciones dignas y desarrollarse desde el punto de vista profesional y también personal", de manera que "la situación del empleo constituye uno de los factores clave en la prevención de la pobreza y la exclusión social; su importancia, de hecho, se ha visto reconocida ampliamente en el enfoque de inclusión activa. Las rentas del trabajo, cuya obtención está vinculada con el empleo estable, constituyen la principal fuente de ingresos de las familias y, por tanto, es uno de los elementos cruciales a tener en cuenta a la hora de considerar a aquellos hogares que están en riesgo de pobreza y exclusión social" (Estrategia Nacional de Prevención y Lucha contra la Pobreza y la Exclusión Social 2019-2023); como objetivo estratégico de los poderes públicos se propone "potenciar el empleo como principal instrumento de inclusión social” (Estrategia española de activación para el empleo 2017-2020, aprobada mediante Real Decreto 1032/2017, de 15 de diciembre). También podemos leer que "el trabajo es el mecanismo por excelencia de integración social. No sólo porque alrededor suyo se articula gran parte del esquema axiológico-valorativo imperante, sino porque opera como fulcro de acceso a otras demandas sociales (vivienda, educación, calidad de vida...)", ALEMÁN PÁEZ, F.: "Grupos vulnerables. Procesos de formación y políticas socio laborales”, Revista Universitaria de Ciencias del Trabajo, no 5, 2004, p. 354; o que las políticas de inclusión social "declaran con rotundidad la importancia del empleo como mecanismo de inclusión", Fernández Villazón, L.A. (2016), op. cit., p. 131.

56. Interesante reflexión sobre empleo e inclusión en Alemán Páez, F., op. cit., p. 354, donde distingue tres binomios: zona de marginación-exclusión laboral; zona de vulnerabilidad-trabajo precario; y zona de integración-trabajo estable. 
duce el fenómeno de las personas trabajadoras pobres, en el que el empleo no blinda frente a la exclusión social ${ }^{57}$.

Esa realidad de trabajadoras y trabajadores pobres (working poor) dista de ser marginal, al contrario, parece una realidad cada vez más extendida. El reflejo de las recetas neoliberales ha traído consigo mermar la eficacia del derecho del trabajo, reduciendo así las garantías y condiciones laborales mínimas para las personas trabajadoras, entre ellas, el salario.

Un supuesto, este sí muy particular, en el que el empleo no es la mejor herramienta para la inclusión social, es el de las personas con trastorno del espectro autista. Este tipo de personas con discapacidad necesita un seguimiento individualizado para observar cómo le afecta psicológicamente el empleo. No es infrecuente que la actividad laboral les provoque situaciones de estrés, de manera que puede producir un efecto perjudicial, en estos casos.

En definitiva, para concluir este apartado, conviene subrayar la idea de que los grupos vulnerables lo son por sus características de vulnerabilidad social, que los llevan a situaciones de exclusión social, o riesgo de la misma. Salvo los últimos supuestos comentados, parece evidente que, para la inclusión social, lo más eficaz es la inclusión laboral. Por eso, en el siguiente apartado nos centraremos en el empleo de los grupos vulnerables.

\section{El acceso al empleo de los grupos vulnerables}

Para analizar la relación entre los grupos vulnerables y el empleo, nos centraremos en el derecho español, por constituir el acceso al empleo una materia competencia exclusiva del Estado ${ }^{58}$. Así, de entrada, nos damos cuenta de que ni la principal norma en materia de empleo ${ }^{59}$, ni tampoco la referencia ineludible sobre el estatuto

57. "Las bajas oportunidades de empleo y las condiciones laborales precarias en los jóvenes, han multiplicado por tres la tasa de trabajadores pobres de entre 18 y 24 ańos desde 2007 a 2014 (de 7,1 por 100 a 21,3 por 100), en una realidad que se ha incrementado, aunque en menor medida, en toda Europa (8,9 por 100)", RODRÍGUEZ ESCANCIANO, S. \& GÓMEZ GARCÍA, F.X.: "La edad como factor de vulnerabilidad social: algunos factores merecedores de preocupación”, Derecho de las relaciones laborales, no 5, 2018, p. 10.

58. El art. 149.1.1 a de la Constitución atribuye al Estado competencia exclusiva sobre la regulación de las condiciones básicas que garanticen la igualdad de todos los españoles en el ejercicio de los derechos y en el cumplimiento de los deberes constitucionales, entre los que se encuentra el derecho al trabajo (art. 35.1). Además, el art. 149.1.7 $\mathrm{CE}$ otorga al Estado competencia exclusiva en materia de legislación laboral.

59. Real Decreto Legislativo 3/2015, de 23 de octubre, por el que se aprueba el texto refundido de la Ley de Empleo. 
jurídico de las personas trabajadoras ${ }^{60}$, realizan una sola mención literal a los grupos vulnerables.

En el Estatuto de los trabajadores, lo más afín a los grupos vulnerables son los colectivos respecto de los cuales se prohíbe la discriminación en el acceso al empleo (art. 17 ET). En el caso de la Ley de empleo, también podemos encontrar una noción cercana: los colectivos prioritarios (art. $30 \mathrm{LE).}$

\subsection{No discriminación en el acceso al empleo}

El principio de igualdad y no discriminación aparece proclamado, con el máximo rango normativo, en la Constitución española. La igualdad se erige en valor superior del ordenamiento jurídico (art. $1 \mathrm{CE}$ ); y el art. $14 \mathrm{CE}$, pórtico del capítulo dedicado a los derechos y libertades, proclama la igualdad ante la ley, sin que pueda prevalecer discriminación alguna por razón de nacimiento, raza, sexo, religión, opinión o cualquier otra condición o circunstancia personal o social.

De esa manera, la igualdad se predica como principio general aplicable a todas las personas, siguiendo la estela de la égalité de la Revolución Francesa, mientras que la no discriminación llama a poner el foco en colectivos típica e históricamente discriminados ${ }^{61}$.

El máximo intérprete constitucional nos ilustra sobre la noción de discriminación que encierra el art. $14 \mathrm{CE}$, al indicar que representa una explícita interdicción del mantenimiento de determinadas diferenciaciones históricamente muy arraigadas y que han situado, tanto por la acción de los poderes públicos, como por la práctica social, a sectores de la población en posiciones no sólo desventajosas, sino abiertamente contrarias a la dignidad de la persona que reconoce el art. 10 de la C.E. (STC 128/1987, de 16 de julio) ${ }^{62}$.

60. Real Decreto Legislativo 2/2015, de 23 de octubre, por el que se aprueba el texto refundido de la Ley del Estatuto de los Trabajadores.

61. "La aplicación del artículo 14 está sujeta a dos cánones de enjuiciamiento de distinta intensidad: a) el juicio ordinario de igualdad, aplicable a las diferencias normativas de cualquier clase; $y$ b) el juicio estricto de igualdad, que debe recaer sobre las fundadas en alguno de los motivos prohibidos de discriminación. Residiendo la diferencia en el hecho de que, mientras en el primero se parte de una presunción de legitimidad de la intervención legislativa, en el segundo el punto de arranque viene marcado por la sospecha de la falta de justificación de la diferencia basada en un factor constitucionalmente prohibido, que solo puede ser contrarrestada si se demuestra que cuenta con un fundamento claro en el propio texto constitucional, siendo los beneficios reportados por su aplicación, a la luz de los valores consagrados por este, superiores a los perjuicios pueda causar al colectivo afectado", SANGUINETI RAYMOND, W.: "La edad: ¡cenicienta de las discriminaciones?", Trabajo y Derecho, no 59, 2019, p. 7.

62. Destacando el "carácter rechazable u odioso de la utilización como criterio de diferenciación de las condiciones personales o sociales contenidas en la lista abierta del art. 14", RODRÍGUEZ-PIÑERO \& BRA- 
(pp. 15-53)

Desde luego, la prohibición de discriminación no alcanza únicamente a eventuales vulneraciones efectuadas por los poderes públicos. Resulta pacífica la idea de que la garantía constitucional proyecta su fuerza vinculante a las discriminaciones (horizontales) producidas entre sujetos privados, como el caso, que aquí interesa, de la discriminación en al acceso al empleo que puede provocar una empresa, al no contratar a una persona por su pertenencia a alguno de los grupos vulnerables ${ }^{63}$.

Como desarrollo legal de ese mandato constitucional, en materia de acceso al empleo, el art. 17.1 ET declara la nulidad de normas, contratos, y decisiones unilaterales del empresario que den lugar en el empleo... a situaciones de discriminación directa o indirecta desfavorables por razón de edad o discapacidad o a situaciones de discriminación directa o indirecta por razón de sexo, origen, incluido el racial o étnico, estado civil, condición social, religión o convicciones, ideas políticas, orientación o condición sexual, adhesión o no a sindicatos y a sus acuerdos, vínculos de parentesco con personas pertenecientes a o relacionadas con la empresa y lengua dentro del Estado español.

Encontramos de esa manera la versión jurídico-positiva laboral de los grupos vulnerables, proscribiendo su discriminación en el acceso al empleo, por tratarse de colectivos tradicionalmente desfavorecidos. Podemos afirmar, desde luego, que los listados de grupos vulnerables (vid. supra, p.8) y de colectivos cuya discriminación se prohíbe, se asemejan notablemente ${ }^{64}$.

Podemos concluir este apartado subrayando que las personas pertenecientes a los grupos vulnerables tienen derecho al trabajo (art. 35.1 CE), en igualdad de condiciones con respecto al resto de personas, sin que puedan ser objeto de discriminación, de manera que eventuales actos jurídicos discriminatorios en su acceso al empleo devendrían nulos y sin efecto. También hay que destacar que, dentro del amplio espectro

VO-FERRER, M.: "Nuevas dimensiones de la igualdad: no discriminación y acción positiva", Persona y Derecho, no 44, 2001, p. 224.

63. Refiriéndose a la doctrina del TC, Rodríguez-Piñero y Bravo-Ferrer, M., op. cit., p. 222., indica que "ese trato calificado como medida discriminatoria se ha referido no a una norma o acto de los poderes públicos sino a actuaciones de poderes privados, en concreto, el primer supuesto fue un despido calificado de discriminatorio por contrario al derecho de la libertad sindical".

64. Subraya el vínculo entre vulnerabilidad e igualdad, Miñarro Yanini, M., op. cit., p. 5, "prima facie, la vulnerabilidad apunta a la desigualdad, por lo que, proyectada al campo jurídico-social, podría decirse que constituye una quiebra del principio de igualdad que determina que unos grupos que se hallen afectos de una circunstancia de índole socio-económica determinada se encuentren en peor situación que otros que no lo están". En idéntico sentido, Fernández Villazón, L.A. (2016), op. cit., p. 118, afirma que "cabe deducir una clara relación entre la idea de grupo vulnerable y los principios de igualdad y no discriminación. De alguna manera, al legislador comunitario los más vulnerables se le presentan principalmente como grupos de personas más expuestos a situaciones indeseables de discriminación”. 
de la discriminación laboral, "la fase de acceso al empleo es, de lejos, la más difícil de controlar por cualquier política antidiscriminatoria" ${ }^{65}$.

\subsection{Los colectivos prioritarios}

Siendo el objetivo principal del presente artículo, como su propio título indica, la inclusión socio-laboral de los grupos vulnerables, a partir de ahora me centraré en los colectivos prioritarios que identifica la ley de empleo, porque se trata del reflejo jurídico, en el derecho del empleo, de la noción sociológica amplia de los grupos vulnerables ${ }^{66}$.

Así, el art. 30 de la Ley de empleo ${ }^{67}$ ordena al Gobierno del Estado y a las Comunidades Autónomas adoptar programas especificos destinados a fomentar el empleo de las personas con especiales dificultades de integración en el mercado de trabajo, especialmente jóvenes, con particular atención a aquellos con déficit de formación, mujeres, parados de larga duración, mayores de 45 años, personas con responsabilidades familiares, personas con discapacidad o en situación de exclusión social, e inmigrantes, con respeto a la legislación de extranjería, u otros que se puedan determinar, en el marco del Sistema Nacional de Empleo.

Así, la principal norma estatal en materia de inclusión socio-laboral, la ley de empleo, nos identifica ocho colectivos prioritarios, y termina dejando la puerta abierta a la inclusión futura de otros grupos. Para determinar cuáles son los colectivos prioritarios con mayores dificultades de acceso al empleo ${ }^{68}$, los poderes públicos disponen de un instrumento objetivo: los datos estadísticos sobre inactividad y desempleo de cada colectivo, en comparación con la población general, como veremos infra.

65. Sanguineti Raymond, W., op. cit., p. 1.

66. "Salta a la vista que estos colectivos priorizados de la política de empleo coinciden en gran medida con los grupos tradicionalmente considerados vulnerables”, Fernández Villazón, L.A. (2016), op. cit., p. 130, de manera que "el concepto de colectivos priorizados en materia de empleo se mueve en un plano parcialmente distinto... siendo en él más relevante la situación efectiva de desempleo que la pertenencia a un grupo tradicionalmente discriminado socialmente", ibid., p. 131.

67. Real Decreto Legislativo 3/2015, de 23 de octubre, por el que se aprueba el texto refundido de la Ley de Empleo.

68. Creo que el legislador se hace acreedor de una crítica técnico-jurídica por referirse en ese art. 30 a las especiales dificultades de integración en el mercado de trabajo. Se trata de una falta de rigor que observamos con demasiada frecuencia. La dificultad no está en acceder al mercado de trabajo, porque la mera inscripción como demandante de empleo ubica a una persona desempleada en su seno; la dificultad estriba en el acceso al empleo. En el art. 10.4 de la misma ley podemos leer, esta vez de forma correcta, una referencia a aquellos colectivos que tienen mayor dificultad en el acceso o permanencia en el empleo. 
(pp. 15-53)

Por ello, parece muy acertado que la lista se configure como abierta, porque la evolución socioeconómica y las estadísticas serán las que indiquen que un nuevo colectivo debe ser incorporado a la lista o, en el mejor de los casos, que un colectivo incluido en ella debe dejar de estarlo.

El diseño de las políticas activas de empleo, dirigidas a fomentarlo, se realiza mediante la denominada Estrategia española de activación para el empleo, prevista en el art. 10 de la Ley de empleo. En este momento está vigente la Estrategia 2017-2020, que contiene referencias específicas a cada uno de los colectivos prioritarios del art. 30, con la única excepción de las personas con responsabilidades familiares, ausencia que debemos valorar como anecdótica, quizás debida a los contornos difusos de ese colectivo $^{69}$. Dicha estrategia plurianual se ejecuta mediante el correspondiente Plan Anual de Política de Empleo, instrumento previsto en el art. 11.2 de la Ley de empleo. El último vigente es el de 2019, y ahí sí que se mencionan explícitamente los ocho colectivos prioritarios que enumera el art. 30 de la Ley de empleo ${ }^{70}$.

A continuación, estudiaremos brevemente las principales características de esos ocho grupos vulnerables, que determinan su categorización como colectivo prioritario, en el mismo orden que establece el art. 30 de la ley de empleo.

\subsubsection{Jóvenes, con particular atención a aquellos con déficit de formación}

Como se ha indicado más arriba, los datos más elocuentes para acreditar la condición de colectivo con especiales dificultades para acceder al empleo, hay que buscarlos en los indicadores de actividad y paro.

Así, podemos observar que los jóvenes entre 16 y 24 años muestran una tasa de actividad del 34,66\%, frente al 86,37\% en el tramo entre 25 y 54 ańos $^{71}$. Casi dos terceras partes $(65,34 \%$ de inactividad) de esas personas jóvenes en edad de trabajar ni siquiera buscan empleo. Aunque ello se pueda explicar, en buena parte, en que se trata de estudiantes, la diferencia con respecto al $86,37 \%$ parece muy abultada.

Más elocuente resulta el contraste en el indicador de la tasa de desempleo, donde sólo se tienen en cuenta a las personas jóvenes que quieren trabajar, pero no logran

69. Estrategia española de activación para el empleo 2017-2020, aprobada mediante Real Decreto 1032/2017, de 15 de diciembre.

70. Resolución de 12 de marzo de 2019, de la Secretaría de Estado de Empleo, por la que se publica el Acuerdo del Consejo de Ministros de 8 de marzo de 2019, por el que se aprueba el Plan Anual de Política de Empleo para 2019 (BOE de 15 de marzo de 2019).

71. Datos del primer trimestre de 2020, extraídos de la Encuesta de Población Activa (EPA), a nivel de todo el Estado (www.ine.es). 
(pp. 15-53)

empleo. En este caso, los jóvenes entre 16 y 24 años tienen una tasa del 32,99\%, frente al $13,39 \%$ de paro en el tramo entre 25 y 54 ańos $^{72}$.

Si nos preguntamos por qué, la respuesta debe poner el foco en el eventual déficit formativo, como el propio art. 30 de la ley de empleo expresamente indica ${ }^{73}$, y en la inexperiencia laboral. Eso provoca el efecto perverso de que, además de sufrir una barrera para acceder al empleo mucho más alta que el resto de la población, las personas jóvenes a menudo logran su primer empleo mediante contratos precarios con condiciones laborales muy escasas ${ }^{74}$.

Aunque la edad sea un elemento objetivo, no es de recibo que se trate de esa manera peyorativa, globalmente, a todo un segmento de población. La cuestión merecería un estudio individualizado, que las empresas pueden realizar mediante procesos de selección adecuados ${ }^{75}$.

\subsubsection{Mujeres}

Las mujeres, a pesar de ser un colectivo mayoritario en la población mundial, han resultado históricamente discriminadas con respecto a los hombres, y siguen estándolo. La profusión de normas proclamando la igualdad y proscribiendo la discriminación, en materia de empleo, no han producido, ni de lejos, el resultado deseable ${ }^{76}$.

72. Datos del primer trimestre de 2020, extraídos de la Encuesta de Población Activa (EPA), a nivel de todo el Estado (www.ine.es).

73. Como consecuencia de las amplias necesidades formativas, alertando sobre el riesgo de la "burbuja formativa", ALEMÁN PÁEZ, F.: "La rueda de Ixión del empleo juvenil", Revista de la Fundación $1^{\circ}$ de Mayo, 58, 2014, p. 20.

74. Compartimos la reflexión de que "en modo alguno ha de prevalecer, como hasta ahora, la inserción laboral a toda costa a través de una devaluación progresiva de las condiciones de trabajo", MEGINO FERNÁNDEZ, D.: "Jóvenes y mercado de trabajo: precariedad a cambio de inserción laboral", Revista de Trabajo y Seguridad Social-CEF, no 383, 2015, p. 134. En la misma línea, CARDONA RUBERT, Ma ${ }^{a}$ B. \& CABEZA PEREIRO, J.: "La discriminación por edad sobre las mujeres mayores", Trabajo y Derecho, no 59, 2019, p. 3, "por demasiado jóvenes, existe una tendencia casi inevitable a retribuirlas menos, en no pocas ocasiones a través de una legislación permisiva o incluso incentivadora de diferencias muy desproporcionadas. Se las somete a un proceso de inserción laboral caracterizado por una precariedad intensa, por una negación casi absoluta de los derechos de estabilidad en el empleo".

75. "Partiendo de que se está más cerca de cuestiones de aprendizaje... que de la simple biología, las divisiones grupales van a ser siempre arbitrarias, no pudiendo establecerse categorías universalmente válidas que, además, variarán regionalmente según los factores culturales y jurídicos vigentes en cada época”, Rodríguez Escanciano, S., Gómez García, X., op.cit., p. 7.

76. "Nadie duda que en la actualidad, a pesar de las diversas y múltiples medidas adoptadas en relación con la discriminación de género en aras a erradicar las discriminatorias que se producen tanto en el acceso al 
Para sostener esa afirmación, nada mejor que los datos más recientes. Si comparamos las tasas de actividad de mujeres y hombres, vemos que alcanza el 53,03\% en el caso de las mujeres, frente al $63,63 \%$ de los hombres ${ }^{77}$. En cuanto a la tasa de paro, es del $16,24 \%$ en la población activa femenina, frente al $12,79 \%$ en la masculina ${ }^{78}$.

Esos datos revelan nítidamente que un porcentaje sensiblemente menor de mujeres que de hombres se encuentra en el mercado laboral, trabajando o demandando empleo; y el porcentaje femenino supera con creces al masculino en el indicador del paro, donde se busca empleo pero no se encuentra.

Desde luego, en el caso de las mujeres, nos encontramos con el rocoso obstáculo del prejuicio $^{79}$. Parece pertinente recordar que, con anterioridad al reconocimiento legal de la igualdad, en el siglo XIX se generalizó en Europa la consideración de la mujer como media fuerza (al igual que las niñas y los niños), con respecto al hombre adulto, con la consiguiente minoración del salario y demás condiciones laborales. Calificación de media fuerza que se basaba en el más puro prejuicio, sin evidencia científica alguna, porque no se puede probar lo que no es cierto.

La discriminación legal ha sido superada, no así el prejuicio, ni la discriminación fáctica.

\subsubsection{Parados de larga duración}

El colectivo de personas paradas de larga duración está constituido por aquellas personas desempleadas que llevan mucho tiempo, como mínimo un año, como demandantes de empleo, y sin lograr acceder al mismo.

Se trata de un segmento, dentro del universo de la población desempleada, en el que el mero transcurso del tiempo, como demandante de empleo y sin lograr trabajar, es un claro indicador de que tiene especiales dificultades para acceder al empleo.

mercado de trabajo como en la propia relación laboral, subsisten situaciones totalmente discriminatorias para con la mujer. De entre todas las posibles conductas discriminatorias, posiblemente, las que se producen en el momento de acceso al mercado de trabajo sean las más difíciles de controlar", POQUET CATALÁ, R.: "De nuevo con la discriminación por razón de sexo en el empleo. Última doctrina judicial comunitaria”, Derecho de las Relaciones Laborales, no 2, 2019, p. 1.

77. Datos del primer trimestre de 2020, extraídos de la Encuesta de Población Activa (EPA), a nivel de todo el Estado (www.ine.es).

78. Datos del primer trimestre de 2020, extraídos de la Encuesta de Población Activa (EPA), a nivel de todo el Estado (www.ine.es).

79. "Estereotipos sociales que ponen en tela de juicio su fiabilidad, aptitud y profesionalidad y que la someten a una sexualización que las perjudica en sus proyectos laborales", Cardona Rubert, Ma.B., Cabeza Pereiro, J., op. cit., p. 4. 
Son personas en las que se corre el riesgo de la cronificación del desempleo, que en algunos casos se convierte en realidad.

Si acudimos a las estadísticas, podemos observar que, en el año 2018, un 6,4\% de las personas desempleadas llevaba más de un año sin lograr empleo ${ }^{80}$, por lo tanto, ese sería el porcentaje, en el ańo indicado, de personas en desempleo de larga duración, en relación al número total de personas desempleadas.

\subsubsection{Mayores de 45 años}

En general, los trabajadores maduros constituyen un grupo vulnerable en el acceso al trabajo. La ley de empleo delimita ese concepto, al establecer el umbral determinado de los 45 años, siguiendo así la estela de cierta tradición en el ámbito de las políticas de empleo ${ }^{81}$.

Actualmente, no existe ninguna condición legal relacionada con el cumplimiento de determinada edad máxima como elemento que impida el acceso al empleo. Bien es cierto que esa posibilidad se permite en el caso de los convenios colectivos, siempre como medida de fomento del empleo de otras personas, y cuando se garantice que la persona obligada a dejar el empleo percibirá el $100 \%$ de su pensión de jubilación ${ }^{82}$.

El último dato estadístico disponible sobre parados registrados es elocuente. De 3.548.312 personas demandantes de empleo registradas, prácticamente la mitad, 1.755.700, tienen 45 ańos o más, lo que supone el $49.47 \%{ }^{83}$.

Desde luego, la dificultad de este colectivo para acceder al empleo está fuera de toda duda, $y$, además, se acrecienta según avanza la edad ${ }^{84}$. Cuando nos preguntamos por los motivos, la cuestión se vuelve compleja, porque la edad avanzada objetiva-

80. Encuesta de Población Activa (EPA), a nivel de todo el Estado (www.ine.es).

81. Se trata de la "transición entre la edad adulta y la vejez", Rodríguez Escanciano, S., Gómez García, X., op.cit., p. 8.

82. Disp. adic. 10 del Real Decreto Legislativo 2/2015, de 23 de octubre, por el que se aprueba el texto refundido de la Ley del Estatuto de los Trabajadores. En el caso de los funcionarios públicos, se permite su jubilación forzosa, a partir de los 65 ańos, en virtud del art. 67.3 del Real Decreto Legislativo 5/2015, de 30 de octubre, por el que se aprueba el texto refundido de la Ley del Estatuto Básico del Empleado Público.

83. Datos marzo de 2020, a nivel de todo el Estado (www.sepe.es).

84. "Existen fundados indicios de que la edad, singularmente en su franja superior, constituye hoy la principal causa de discriminación en el ámbito de las relaciones laborales, por encima incluso del sexo", y "a partir de los 55 años las oportunidades de acceso al mismo se tornan prácticamente nulas, sin que puedan establecerse diferencias sustanciales en función del sector de actividad, la profesión y el nivel de cualificación o el tipo de esfuerzo requerido", Sanguineti Raymond, W., op. cit., p. 1. 
(pp. 15-53)

mente puede suponer una merma de capacidad laboral, pero esa circunstancia objetiva envuelve e invisibiliza numerosos supuestos de discriminación antijurídica, y profundamente injusta ${ }^{85}$.

Si la edad produce incapacidad laboral, el derecho del trabajo ya cuenta con el despido objetivo, basado precisamente en la ineptitud para desempeñar la actividad laboral contratada ${ }^{86}$. Por lo tanto, la edad no puede erigirse en barrera objetiva en el acceso al empleo, ni en causa sustantiva de despido, debiendo protegerse frente al trato discriminatorio prohibido.

A menudo se confunden prejuicios y evidencias científicas ${ }^{87}$. Ello redunda en un notable perjuicio para las personas mayores de 45 años, fuertemente discriminadas, $y$ cuya discriminación, con demasiada frecuencia, pasa desapercibida.

\subsubsection{Personas con responsabilidades familiares}

El colectivo de personas con responsabilidades familiares, nos sitúa, en primer lugar, ante la ausencia de concepto jurídico, teniendo como efecto la consiguiente

85. "Partiendo de que se está más cerca de cuestiones de aprendizaje y deterioro cognitivo que de la simple biología, las divisiones grupales van a ser siempre arbitrarias, no pudiendo establecerse categorías universalmente válidas que, además, variarán regionalmente según los factores culturales y jurídicos vigentes en cada época”, Rodríguez Escanciano, S., Gómez García, X., op.cit., p. 7.

86. Art. 52 del Estatuto de los Trabajadores.

87. La Sentencia del Tribunal Superior de Justicia de Cantabria 291/2007, de 28 marzo, (rec. 249/2007), subraya los estereotipos sociales de "la menor competitividad y fuerza física o la resistencia al cambio". A las personas maduras se les achaca "falta de adaptación, de reciclaje profesional, encarecimiento de los costes laborales, cargas familiares y mayor propensión a las bajas laborales y al absentismo", MONEREO PÉREZ, J.L., MOLINA NAVARRETE, C. \& QUESADA SEGURA, R. et. al.: Manual de politica y derecho del empleo, Tecnos, Madrid, 2011, p. 389. Sanguineti Raymond, W., op. cit., p. 2., indica con acierto que "la madurez se presenta vinculada con el deterioro físico, la obsolescencia de los conocimientos, falta de flexibilidad e interés por adquirir nuevos saberes o la incapacidad de adaptación a las nuevas tecnologías. Poco importa que la evidencia científica ponga de manifiesto, como se ha destacado, que la edad constituye un fenómeno altamente individualizado, que depende en gran medida de cada sujeto. Finalmente estos estereotipos terminan por impregnar el sistema de creencias de los individuos, impulsándolos a adoptar decisiones en perjuicio de los integrantes de ambos colectivos". Como sostienen Rodríguez Escanciano, S., Gómez García, X., op.cit., p. 9, "en definitiva, la edad y el envejecimiento son heterogéneos e individualizados, no estando la capacidad para trabajar únicamente determinada por la edad”. Certera reflexión también en Cardona Rubert, Ma.B., Cabeza Pereiro, J., op. cit., p. 3, "la construcción social de la tercera edad está sustentada por presuposiciones, en su mayoría negativas, ligadas a la enfermedad o a la salud deficiente, a la falta de proyectos y de potencial para innovar, a la obsolescencia de las capacidades o a la extemporaneidad de los valores de las personas mayores. Los estereotipos negativos redundan en que se les atribuyan papeles subalternos, en el contexto de una sociedad que, aparentemente, poco debe esperar de ellas. Es verdad que las condiciones físicas y psíquicas van evolucionando con el tiempo, pero también lo es que la tercera edad es un colectivo cada vez más heterogéneo y que el envejecimiento resulta un proceso más relativo y aplazado en el tiempo, en el que caben muchos matices". 
inseguridad jurídica. La ley de empleo no nos aporta luz al respecto, y tampoco lo hace, en desarrollo de la misma, la Estrategia española de activación para el empleo 2017-2020, ni el Plan Anual de Política de Empleo 2019.

Por afinidad con la temática que nos ocupa, el acceso al empleo, parece oportuno acudir al concepto acunado en el ámbito de las políticas pasivas de empleo, concretamente en la regulación del subsidio por desempleo, donde se indica que se entenderá por responsabilidades familiares tener a cargo al cónyuge, hijos menores de veintiséis años o mayores incapacitados, o menores acogidos, cuando la renta del conjunto de la unidad familiar asi constituida, incluido el solicitante, dividida por el número de miembros que la componen, no supere el 75 por ciento del salario minimo interprofesional, excluida la parte proporcional de dos pagas extraordinarias. No se considerará a cargo el cónyuge, hijos o menores acogidos, con rentas de cualquier naturaleza superiores al 75 por ciento del salario minimo interprofesional, excluida la parte proporcional de dos pagas extraordinarias (art. 275 de la Ley de seguridad social) ${ }^{88}$.

Por lo tanto, aunque la definición transcrita se circunscribe, técnicamente, al ámbito del subsidio por desempleo, resulta reveladora de la noción genérica de persona con responsabilidades familiares, que se construye en torno a la conjunción de los elementos de tener familiares a cargo, y renta económica escasa para hacer frente a esa situación. De esa manera, esas personas, en su gran mayoría mujeres, encuentran especiales dificultades para acceder al empleo, por su exigente situación familiar y necesidad económica, unida a la disposición limitada de tiempo ${ }^{89}$.

\subsubsection{Personas con discapacidad}

Sin duda, en las personas con discapacidad encontramos el más clásico de los grupos vulnerables que sufren discriminación ${ }^{90}$. Más allá del ámbito del acceso al empleo, objeto de este estudio, este colectivo ha sufrido tremendas atrocidades ${ }^{91}$. Es

88. Real Decreto Legislativo 8/2015, de 30 de octubre, por el que se aprueba el texto refundido de la Ley General de la Seguridad Social.

89. El art. 1 del Convenio no 156 OIT sobre los trabajadores con responsabilidades familiares (1981), pone el acento en que tales responsabilidades limiten sus posibilidades de prepararse para la actividad económica y de ingresar, participar y progresar en ella.

90. Por ese motivo, "las políticas activas de empleo dirigidas a este colectivo son las que cuentan con mayor tradición en nuestro país, constituyendo precisamente punto de arranque de las políticas de empleo diferenciadas subjetivamente", Monereo Pérez, J.L., Molina Navarrete, C., Quesada Segura, R. et. al., op. cit., p. 383.

91. Mención aparte merece el caso del nazismo, que consideraba desechables estas personas, y puso en marcha un programa de exterminación sistemática de las personas con discapacidad, preludio de las cámaras de gas que sufrió la población judía en el III Reich. 
(pp. 15-53)

cierto que el derecho humanitario ha avanzado notablemente en la proclamación de la igualdad y dignidad de las personas con discapacidad, habiendo recorrido un largo camino, que comienza en la propia denominación del colectivo ${ }^{92}$.

La discapacidad es aquella situación que resulta de la interacción entre las personas con deficiencias previsiblemente permanentes y cualquier tipo de barreras que limiten o impidan su participación plena y efectiva en la sociedad, en igualdad de condiciones con las demás ${ }^{3}$. Se trata de personas a las que, tras la pertinente evaluación multidisciplinar (personal médico, psicólogo, y trabajador social), se les reconoce un grado de discapacidad mínimo del 33\%. La discapacidad puede ser física, sensorial, o psíquica (mental o intelectual).

Cuando acudimos a los datos estadísticos, observamos que resultan sumamente reveladores. Así, la tasa de actividad de las personas con discapacidad es del 34,5\%, frente al $77,6 \%$ de las personas sin discapacidad. En cuanto a la tasa de paro, 25,2\% para el primer colectivo, y $15,1 \%$ para el segundo ${ }^{94}$.

Se trata de un colectivo que sufre prejuicios y estereotipos sociales de gran calado, que se reflejan, entre otros muchos ámbitos, como barrera invisible cuando pretenden acceder al empleo ${ }^{95}$.

\subsubsection{Personas en situación de exclusión social}

Más arriba (apdo. 2.4), hemos sostenido la equiparación entre las nociones de grupo vulnerable y personas en situación o riesgo de exclusión social. Ahora debemos centrarnos en el segundo colectivo. Además, el art. 30 de la Ley de empleo considera

92. La expresión persona con discapacidad es no sólo política, sino jurídicamente correcta, por mandato de la disp. adic. 8 de la Ley 39/2006, de 14 de diciembre, de promoción de la autonomía personal y atención a las personas en situación de dependencia: las referencias que en los textos normativos se efectúan a minusválidos y a personas con minusvalia se entenderán realizadas a personas con discapacidad. A partir de la entrada en vigor de la presente Ley, las disposiciones normativas elaboradas por las Administraciones públicas utilizaran los términos persona con discapacidad o personas con discapacidad para denominarlas. Como exponía en otro lugar, "no resulta, desde luego, intrascendente que a la misma persona se le califique como deficiente, subnormal, minusválido, retrasado mental, o persona con discapacidad. Actualmente, la expresión persona con discapacidad se encuentra plenamente arraigada en el ámbito del Derecho, en el contexto de las políticas de igualdad y no discriminación, por ser debidamente respetuosa y no peyorativa", BENGOETXEA ALKORTA, A.: "Economía social e inserción laboral de las personas con discapacidad", Revista Vasca de Administración Pública, no 99-100, 2014, p. 529.

93. Art. 2 a) del Real Decreto Legislativo 1/2013, de 29 de noviembre, por el que se aprueba el Texto Refundido de la Ley General de derechos de las personas con discapacidad y de su inclusión social (LGDPCD).

94. Datos de 2018, a nivel de todo el Estado (www.ine.es).

95. En ese sentido, Alemán Páez, F., op. cit., p. 352; MARTÍN PUEBLA, E.: "Igualdad de trato y no discriminación por edad, discapacidad y orientación sexual”, Trabajo y Derecho, nº Extra 7, 2018, p. 13. 
colectivo prioritario a las personas en situación de exclusión social, sin incluir a las personas en riesgo de estarlo. Puede ser una omisión debida a la falta de rigor, o, por el contrario, podría ser una decisión consciente. Me inclino por la segunda opción. Tiene sentido que, en el momento de acceder al empleo, se considere colectivo prioritario solo a las personas en situación de exclusión social materializada.

Llegados a este punto, nos encontramos ante un colectivo, personas en situación de exclusión social, sin un concepto jurídico claro, más allá de la claridad de su propia denominación. Sí existe una enumeración legal de esta categoría de personas, en la Ley de empresas de inserción, como hemos podido observar supra (apdo. 2.4). También hay que destacar el vínculo conceptual entre pobreza y exclusión social, cuyo máximo exponente puede ser la vigente Estrategia nacional de prevención y lucha contra la pobreza y la exclusión social (2019-2023).

Sea como fuere, aún careciendo de concepto jurídico, podemos concluir que es correcta la ubicación de las personas en situación de exclusión social entre los colectivos prioritarios. A consecuencia de su desfavorable situación socieconómica, tienen especiales dificultades para acceder al empleo, debido a sus propias condiciones subjetivas de empleabilidad, y también a los prejuicios que pueden sufrir.

\subsubsection{Inmigrantes}

Cuando se trata a las personas inmigrantes como colectivo prioritario para el acceso al empleo, conviene realizar una delimitación preliminar.

Se está aludiendo a inmigrantes extracomunitarios, porque las personas con nacionalidad de alguno de los países de la Unión Europea gozan de un estatuto particular, en virtud del principio de libre circulación ${ }^{96}$.

Otro aspecto fundamental a tener en cuenta es que los extranjeros, por el mero de hecho de serlo, no gozan del principio de igualdad con respecto a los españoles para el acceso al empleo ${ }^{97}$. De manera que los extranjeros mayores de dieciséis años precisarán, para ejercer cualquier actividad lucrativa, laboral o profesional, de la correspondiente autorización administrativa previa para residir y trabajar ${ }^{98}$. Para expedir ese

96. Art. 45 del Tratado de Funcionamiento de la Unión Europea. Más allá del art. 30, toda la ley de empleo, cuando se refiere a la inmigración, sistemáticamente hace referencia a las personas extracomunitarias.

97. El art. 35.1 CE reconoce el derecho al trabajo únicamente a los españoles, a partir de ahí, tempranamente indicó el Tribunal Constitucional que "constitucionalmente no resulta exigible la igualdad de trato entre los extranjeros... y los espańoles en materia de acceso al trabajo y no existe tratado que así lo imponga, ya sea multilateral o bilateral" (STC 107/1984, de 23 de noviembre).

98. Art. 36.1 de la Ley Orgánica 4/2000, de 11 de enero, sobre derechos y libertades de los extranjeros en España y su integración social (LOEX). 
(pp. 15-53)

permiso de trabajo, la autoridad laboral correspondiente, tendrá en cuenta la situación nacional de empleo ${ }^{99}$. Queda clara la posición legalmente rezagada de las personas extranjeras en la carrera para lograr un empleo ${ }^{100}$. Ahora bien, si logran empleo, la ley les garantiza estricta igualdad en las condiciones laborales ${ }^{101}$.

Tras realizar esa delimitación, los últimos datos disponibles nos muestran claramente por qué los inmigrantes son considerados colectivo prioritario para acceder al empleo: $23,21 \%$ de tasa de paro, frente al $13,35 \%$ de los españoles ${ }^{102}$. Cerca del doble.

Los flujos migratorios se han multiplicado con el fenómeno de la globalización económica. Más allá de ese dato económico objetivo, la consideración de las personas inmigrantes como colectivo prioritario se deriva sobre todo de la cuestión del contraste cultural, que a menudo actúa como dificultad ańadida en el acceso al empleo $^{103}$.

\subsection{Acción positiva en favor del acceso al empleo de los colectivos prioritarios}

Desde luego, jurídicamente, los colectivos prioritarios pueden acceder al empleo del mismo modo que el resto de la población, esto es, sin medidas de acción positiva. Pero el hecho de que los indicadores del mercado de trabajo, en términos de actividad y desempleo, nos muestren su dificultad ańadida, hace aconsejable la aplicación de medidas de acción positiva en favor de los mismos.

El planteamiento jurídico-positivo de la cuestión nos lleva, en primer lugar, al art. 14 CE. Como hemos visto supra (apdo. 4.1), dicho precepto constitucional proclama la igualdad de trato y proscribe el trato discriminatorio. Lo que ocurre es que, para ayudar a los colectivos prioritarios, no es suficiente con la igualdad de trato, sino que es necesario poner el horizonte en la igualdad de oportunidades.

Es el art. 9.2 CE el que va más allá de la igualdad formal ex art. $14 \mathrm{CE}$, abogando por la igualdad material, cuando indica que corresponde a los poderes públicos promover las condiciones para que la libertad y la igualdad del individuo y de los grupos en que se

99. Art. 38.1 LOEX.

100. Alertando del riesgo de que ello desemboque en un "enfoque puramente utilitarista" de las personas inmigrantes, VACA BUSTOS, L.: "Legislación y políticas públicas en España, respecto a la inmigración y su inserción en el mercado laboral", Revista de Derecho de la UNED, 25, 2019, p. 809.

101. Art. 10 LOEX.

102. Datos del primer trimestre de 2020, extraídos de la Encuesta de Población Activa (EPA), a nivel de todo el Estado (www.ine.es).

103. Destacando los aspectos de la globalización y el pluralismo cultural, Vaca Bustos, L., op. cit., pp. 790 y ss. 
integra sean reales y efectivas; remover los obstáculos que impidan o dificulten su plenitud y facilitar la participación de todos los ciudadanos en la vida politica, económica, cultural y social. Ese precepto constitucional es el principal asidero jurídico de la acción positiva (expresión que ha dejado obsoleta a la antigua discriminación positiva) ${ }^{104}$. Por consiguiente, "la incidencia del mandato contenido en el art. 9.2... en cuanto se dirige a los poderes públicos... no podrá reputarse de discriminatoria y constitucionalmente prohibida -antes al contrario- la acción de favorecimiento, siquiera temporal, que aquellos poderes emprendan en beneficio de determinados colectivos, históricamente preteridos y marginados, a fin de que, mediante un trato especial más favorable, vean suavizada o compensada su situación de desigualdad sustancial" ${ }^{105}$.

Posteriormente, el referido mandato constitucional ha sido desarrollado, en lo que aquí interesa, en materia de acceso al empleo, por el art. 17 ET, y el art. 30 de la Ley de empleo.

Destacamos, por su estrecha relación con el presente estudio, el siguiente pasaje del art. 17.3: el Gobierno podrá regular medidas de reserva, duración o preferencia en el empleo que tengan por objeto facilitar la colocación de trabajadores demandantes de empleo. Asimismo, el Gobierno podrá otorgar subvenciones, desgravaciones y otras medidas para fomentar el empleo de grupos especificos de trabajadores que encuentren dificultades especiales para acceder al empleo.

Por su parte, el art. 30.1 de la Ley de empleo indica que el Gobierno y las comunidades autónomas adoptarán... programas especificos destinados a fomentar el empleo de las personas con especiales dificultades de integración en el mercado de trabajo. Seguidamente, el art. 30.2 dispone que teniendo en cuenta las especiales circunstancias de estos colectivos, los servicios públicos de empleo asegurarán el diseño de itinerarios individuales $y$ personalizados de empleo que combinen las diferentes medidas y politicas, debidamente ordenadas y ajustadas al perfil profesional de las personas que los integran y a sus necesidades especificas.

Una vez situados en el marco jurídico que le sirve de soporte, pasemos a observar las principales medidas de acción positiva que el ordenamiento vigente recoge, para ayudar a acceder al empleo a los ocho colectivos prioritarios que el art. 30 de la Ley de empleo enumera ${ }^{106}$.

104. En palabras de doctrina muy autorizada al respecto, "la conexión del art. 14 con el 9.2 C.E. impone a los poderes públicos, y también al legislador, hacer realizable y efectiva la no discriminación, removiendo y suprimiendo situaciones discriminatorias, es lo que se ha llamado la jurisprudencia compensadora relacionada con las llamadas medidas de acción positiva”, Rodríguez-Piñero y Bravo-Ferrer, M., op. cit., p. 232.

105. STC 216/1991, de 14 de noviembre.

106. Utilizaremos, como principales referencias sobre el régimen jurídico-positivo, la "Guía de contratos" (marzo 2020); la "Guía de bonificaciones/reducciones a la contratación laboral" (marzo 2020); y el documen- 
(pp. 15-53)

En lo que respecta al colectivo de personas trabajadoras jóvenes, recordemos que el art. 30 de la Ley de empleo ordena prestar particular atención a aquellos con déficit de formación. Como instrumento específico para luchar contra ese problema formativo, tenemos el contrato para la formación y el aprendizaje, con duración mínima de un año y máxima de tres, previsto para trabajadores mayores de dieciséis años y menores de veinticinco, que carezcan de cualificación profesional, y en régimen de alternancia entre actividad laboral retribuida y actividad formativa recibida ${ }^{107}$. Este contrato se encuentra bonificado con reducción de las cuotas empresariales a la seguridad social, que puede alcanzar el $100 \%{ }^{108}$.

En el ámbito del trabajo autónomo, se prevé una bonificación adicional del 30\% sobre la cuota de contingencias comunes, por encima de la bonificación genérica, para trabajadores menores de 30 ańos. En el terreno del autoempleo colectivo, hay subvenciones específicas por la incorporación de desempleados menores de 25 años, que no hayan tenido antes un primer empleo fijo, como socios trabajadores o socios de trabajo a cooperativas o sociedades laborales ${ }^{109}$.

En el caso de las mujeres, no hay una modalidad contractual específica para este colectivo, sino que, de manera transversal, en distintos tipos de contrato, existe una batería de medidas de bonificaciones y reducciones cuando se contrate a mujeres ${ }^{110}$. Hay disposiciones específicas en casos de mujeres víctimas de violencia de género. En algunos casos, la acción positiva a favor de las mujeres se cruza con las medidas del mismo carácter dirigidas a otro colectivo prioritario ${ }^{111}$.

to sobre "Bonificaciones/reducciones a la seguridad social a trabajadores autónomos" (abril 2020), todos ellos publicados y actualizados regularmente por el sepe (www.sepe.es).

107. Su régimen jurídico se encuentra en el art. 11.2 ET, desarrollado por el Real Decreto 488/1998, 27 de marzo.

108. Formalmente, el instrumento del contrato para la formación muestra las características de acción positiva, en lo que se refiere al estricto momento del acceso al empleo. Una vez empleada esa persona joven, las condiciones laborales dejan mucho que desear, comenzando por el salario, porque la retribución del trabajador será proporcional al tiempo de trabajo efectivo, sin incluir el tiempo dedicado a actividad formativa.

109. Hasta 5.500 euros, en virtud de la Orden TAS/3501/2005, de 7 de noviembre, por la que se establecen las bases reguladoras para la concesión de subvenciones para el fomento del empleo y mejora de la competitividad en las cooperativas y sociedades laborales.

110. Como el caso de la conversión de contratos temporales en contratos indefinidos, o del contrato para la formación y el aprendizaje.

111. Como la contratación de personas con discapacidad, o de personas en desempleo de larga duración. 
En materia de trabajo autónomo también podemos encontrar medidas de acción positiva en favor de las mujeres emprendedoras autónomas ${ }^{112}$. En el ámbito de la economía social, existen subvenciones específicas por la incorporación de mujeres desempleadas como socias trabajadoras o de trabajo a cooperativas o sociedades laborales, en los veinticuatro meses siguientes a la fecha del parto, adopción o acogimiento ${ }^{113}$.

En lo que respecta a los parados de larga duración, hay un contrato específico dirigido a promover el acceso al empleo de este colectivo, denominado "contrato indefinido de personas desempleadas de larga duración". Se requiere su inscripción como desempleadas, como mínimo, doce meses antes de la contratación. Su principal incentivo consiste en bonificaciones en las cuotas a la seguridad social ${ }^{114}$.

En el ámbito de la economía social, existen subvenciones específicas por la incorporación de desempleados de larga duración, que hayan estado sin trabajo e inscritos en la oficina de empleo durante al menos doce de los anteriores dieciséis meses, como socios trabajadores o de trabajo a cooperativas o sociedades laborales ${ }^{115}$.

En el caso de personas trabajadoras mayores de 45 años, no hay contrato específico, pero sí subvenciones por la contratación de personas de esa edad en otras modalidades contractuales ${ }^{116}$.

En el ámbito del autoempleo colectivo, podemos encontrar subvenciones específicas por la incorporación de desempleados mayores de 45 años, como socios trabajadores o de trabajo, a cooperativas o sociedades laborales ${ }^{117}$.

Con respecto al colectivo de personas con responsabilidades familiares, podemos observar que en las modalidades contractuales denominadas "contrato temporal de trabajos de interés social" y "contrato temporal de fomento de empleo agrario", constituye requisito de la persona a contratar que sea desempleada y, además, como criterio a tener en cuenta en la selección, se menciona "tener responsabilidades familiares". En ambos contratos se subvencionan tanto los costes salariales como las cotizaciones a la seguridad social.

112. En supuestos como el alta inicial de mujeres autónomas, o la reincorporación por descanso motivado por nacimiento o adopción.

113. Hasta 7.000 euros, en virtud de la Orden TAS/3501/2005, cit.

114. Durante 3 años, 1.300 euros al año, o 1.500 si es mujer.

115. Hasta 5.500 euros, en virtud de la Orden TAS/3501/2005, cit.

116. Contratación de personas con discapacidad, tanto indefinida como temporal. Al igual que hemos visto en el caso de las mujeres, se superponen aquí dos colectivos prioritarios. 
(pp. 15-53)

Pasando al siguiente colectivo, las personas con discapacidad, empezaremos por afirmar que sin duda constituyen el colectivo destinatario del catálogo más abundante y complejo de medidas de acción positiva. En función de su grado de discapacidad, se prevén tres canales de inclusión: servicio ocupacional (terapia ocupacional, sin relación de empleo); empleo protegido (relación laboral especial en centros especiales de empleo); y empleo ordinario ${ }^{118}$.

En el empleo ordinario, la principal medida, ampliamente incumplida en la práctica, es la reserva del $2 \%$ de los contratos para personas con discapacidad, en las empresas cuya plantilla supere las 50 personas trabajadoras ${ }^{119}$. También en el empleo ordinario, hay dos modalidades contractuales específicas para personas con discapacidad, una de duración indefinida y otra temporal (entre uno y tres ańos) ${ }^{120}$. Hay distintas subvenciones, bonificaciones, y deducciones fiscales, para una u otra modalidad, en torno a diversos conceptos como las cotizaciones a la seguridad social, o la adaptación de puestos de trabajo. Se puede considerar también acción positiva la posibilidad de trabajar, mediante relación laboral especial, en un centro especial de empleo. Esta relación laboral está diseñada para su mejor adaptación al trabajo de las personas con discapacidad, mediante los correspondientes servicios de ajuste personal y social ${ }^{121}$.

En materia de empleo autónomo de personas con discapacidad, también existen incentivos, que difieren en función de la base de cotización por la que se opte. En el ámbito del autoempleo colectivo, hay subvenciones específicas por la incorporación de personas con discapacidad, como socias trabajadoras o de trabajo, a cooperativas o sociedades laborales ${ }^{122}$. Por último, y es el único colectivo prioritario con medidas de

118. Para profundizar en esta materia, BENGOETXEA ALKORTA, A., ETXEBARRIA RUBIO, A., MORANDEIRA ARCA, J. et al.: El modelo vasco de inclusión sociolaboral, Universidad del País Vasco / Euskal Herriko Unibertsitatea, 2020.

119. Art. 42.1 del Real Decreto Legislativo 1/2013, de 29 de noviembre, por el que se aprueba el Texto Refundido de la Ley General de derechos de las personas con discapacidad y de su inclusión social (LGDPCD). Se prevén medidas alternativas al cumplimiento de esa norma, entre las cuales se encuentra la constitución de un enclave laboral en la empresa ordinaria, en el que trabajarán, a modo de una contrata, personas con discapacidad pertenecientes a la plantilla de un centro especial de empleo.

120. Además de estas dos modalidades genéricas, hay incentivos en diversas variantes contractuales, como el contrato en prácticas con personas con discapacidad, o la conversión de contratos formativos y temporales en indefinidos.

121. Art. 43 LGDPCD. Esta relación laboral especial también es objeto de diversos incentivos, en los contratos de personas con discapacidad en centros especiales de empleo, tanto en su variante de contrato indefinido como en el contrato temporal.

122. Hasta 10.000 euros, en virtud de la Orden TAS/3501/2005, cit. 
acción positiva en el empleo público, en las ofertas de empleo público se reservará un cupo no inferior al siete por ciento de las vacantes para ser cubiertas entre personas con discapacidad ${ }^{123}$.

Las personas en situación de exclusión social, de manera similar a las personas con discapacidad, cuentan con dos modalidades contractuales específicas, una de duración indefinida y otra temporal (entre uno y tres ańos). Ambas son objeto de varias bonificaciones, por la propia contratación, y por las cotizaciones a la seguridad social ${ }^{124}$. Además, el legislador ha diseñado las empresas de inserción, como ámbito específico destinado al empleo de las personas en situación de exclusión social, con el objetivo de su posterior inserción en alguna empresa ordinaria, como su propio nombre indica ${ }^{125}$.

En materia de economía social, hay subvenciones específicas por la incorporación de personas en situación de exclusión social, como socios trabajadores o de trabajo, a cooperativas o sociedades laborales ${ }^{126}$.

Por último, en el caso del colectivo prioritario de las personas inmigrantes, no hemos encontrado, en sentido jurídico-técnico, ninguna medida de acción positiva para su acceso al empleo.

\section{Conclusiones}

En el presente estudio, hemos observado cómo la génesis de la noción de los grupos vulnerables se encuentra en el derecho internacional humanitario cuando, yendo más allá de la proclamación de derechos humanos elementales, procura que su ámbito de aplicación universal sea real, lo que le empuja a fijarse en los grupos en situación de desventaja con respecto a la sociedad en general.

Hoy en día los grupos vulnerables constituyen un concepto sociológico muy arraigado, en torno a una amplia lista de colectivos (personas con discapacidad, migrantes, mayores, personas con problemas de adicción, etc.). La lista es abierta, y creemos que debe serlo, para que se adecúe a la evolución socioeconómica, que puede conllevar cambios en su contenido.

\section{Art. 59 EBEP.}

124. Además de estas dos modalidades genéricas, hay incentivos en más variantes contractuales, como la contratación de personas en situación de exclusión social en empresas de inserción, tanto en su modalidad de contrato indefinido como en la de contrato temporal.

125. Ley 44/2007, de 13 de diciembre, para la regulación del régimen de las empresas de inserción. 
La noción de los grupos vulnerables es sociológica, y el derecho la ha importado, sin desarrollar un concepto jurídico, lo que provoca inseguridad jurídica. Cada vez hay más menciones en el derecho positivo a los grupos vulnerables, pero sin concepto jurídico. Hemos sostenido en este estudio la viabilidad de construir ese concepto en torno a las personas en riesgo o situación de exclusión social, que nos parece la aproximación más certera.

Al trasladar la cuestión genérica de los grupos vulnerables al terreno de la inclusión laboral, hemos visto que la ley de empleo enumera ocho colectivos prioritarios (jóvenes, mujeres, parados de larga duración, mayores de 45, personas con responsabilidades familiares, personas con discapacidad, personas en situación de exclusión social, e inmigrantes). La lista queda abierta, con buen criterio, para que pueda adaptarse a la evolución de los mismos, y eventual incorporación de nuevos colectivos.

Hemos observado las características que determinan la consideración de cada uno de los ocho como colectivos prioritarios para acceder al empleo. También las principales medidas de acción positiva que se les aplican, como palanca para su inclusión laboral.

Para valorar la efectividad de esa acción positiva, el indicador más objetivo que mide la situación de cada uno de esos ocho colectivos lo encontramos en los datos del mercado de trabajo, señaladamente, inactividad y paro. Los datos disponibles son harto elocuentes. Tras la identificación de los colectivos, y la aplicación de la terapia de la acción positiva, los datos nos indican que la desventaja, además notoria, continúa.

El mercado laboral es implacable, y los prejuicios son más fuertes que las medidas de acción positiva. Medidas que, muy mayoritariamente, giran en torno a incentivos económicos. A falta de evaluaciones fiables sobre la efectividad de esas medidas, parece bastante acertada la denuncia del effet d'aubaine (efecto chollo), de manera que muchas contrataciones subvencionadas se hubieran producido igualmente sin subvención.

La situación del mercado de trabajo tras el paso de la pandemia provocada por el Covid-19 no parece muy halagüeña. Estas líneas se escriben desde la situación de confinamiento. Cabe suponer que la problemática para el acceso al empleo de los colectivos prioritarios se agudizará.

Para mejorar la situación desventajosa de los grupos vulnerables, que hunde sus raíces en prejuicios y discriminaciones, y avanzar hacia una sociedad realmente inclusiva, se requiere educación. En el ámbito de la política del derecho, voluntad firme, e imaginación para diseñar también otras medidas más allá de los incentivos económicos, quizás más coercitivas, procurando romper el prejuicio. Por ejemplo, en la contratación de personas con discapacidad, hay encuestas que muestran que quien prueba, aunque sea bajo presión, mayoritariamente repite. Y, sobre todo, se requiere una conciencia clara de solidaridad. 
(pp. 15-53)

\section{Bibliografía}

ALEMÁN PÁEZ, F.: "La rueda de Ixión del empleo juvenil”, Revista de la Fundación $1^{\circ}$ de Mayo, no 58, 2014.

ALEMÁN PÁEZ, F.: "Grupos vulnerables. Procesos de formación y políticas socio laborales", Revista Universitaria de Ciencias del Trabajo, no 5, 2004.

BAYLOS GRAU, A.P.: "Desigualdad, vulnerabilidad y precariedad en el análisis jurídico de género", Revista de Derecho Social, no 72, 2015.

BENGOETXEA ALKORTA, A., ETXEBARRIA RUBIO, A., MORANDEIRA ARCA, J. et al.: El modelo vasco de inclusión sociolaboral, Universidad del País Vasco / Euskal Herriko Unibertsitatea, 2020.

BENGOETXEA ALKORTA, A.: "Economía social e inserción laboral de las personas con discapacidad”, Revista Vasca de Administración Pública, no 99-100 (en homenaje a Demetrio Loperena Rota), 2014.

CABEZA PEREIRO, J.: Essay on precarious workers and vulnerable persons, Aranzadi, Cizur Menor, 2016.

CABEZA PEREIRO, J., CARDONA RUBERT, M.B., \& FLORES GIMÉNEZ, F. (coords.): Edad, discriminación y derechos, Aranzadi, Cizur Menor, 2019.

CARDONA RUBERT, Ma.B. \& CABEZA PEREIRO, J.: "La discriminación por edad sobre las mujeres mayores", Trabajo y Derecho, no 59, 2019.

FABREGAT MONFORT, G.: La discriminación de género en el acceso al mercado de trabajo, Tirant lo Blanch, Valencia, 2008.

FERNÁNDEZ LIESA, C.R. \& MARIÑO MENÉNDEZ, F.M. (coords.): La protección de las personas y grupos vulnerables en el derecho europeo, Trabajo e Inmigración, Madrid, 2001.

FERNÁNDEZ VILLAZÓN, L.A.: "La OIT y los grupos vulnerables. Especial atención a la vulnerabilidad de género y a la protección de la infancia”, Estudios Financieros-Revista de Trabajo y Seguridad Social, no 434, 2019.

FERNÁNDEZ VILLAZÓN, L.A.: "Grupos vulnerables: apuntes para un concepto jurídico-social”, Estudios Financieros-Revista de Trabajo y Seguridad Social, no 404, 2016.

FERRER LLORET, J. \& SANZ CABALLERO, S. (coords.): Protección de personas y grupos vulnerables. Especial referencia al Derecho Internacional y Europeo, Tirant lo Blanch, Valencia, 2008. 
La inclusión socio-laboral de los grupos vulnerables. Colectivos y formas de inclusión...

(pp. 15-53)

GARCÍA VALVERDE, Ma.D. \& GARCÍA GÓMEZ, I.: "La realidad del Plan de Choque por el Empleo Joven 2019-2021”, Trabajo y Derecho, no 60, 2019.

MARTÍN PUEBLA, E.: "Igualdad de trato y no discriminación por edad, discapacidad y orientación sexual", Trabajo y Derecho, no Extra 7, 2018.

MARTÍNEZ BARROSO, M.R.: Influencia de la edad en las relaciones laborales: acceso al empleo y protección social, Aranzadi, Cizur Menor, 2018.

MEGINO FERNÁNDEZ, D.: "Jóvenes y mercado de trabajo: precariedad a cambio de inserción laboral”, Revista de Trabajo y Seguridad Social-CEF, no 383, 2015. MINAARRO YANINI, M.: "La protección socio-laboral de los refugiados como grupo vulnerable: balance crítico y propuestas de mejora”, Nueva revista española de derecho del trabajo, no 203, 2017.

MONEREO PÉREZ, J.L., MOLINA NAVARRETE, C., QUESADA SEGURA, R. et. al.: Manual de politica y derecho del empleo, Tecnos, Madrid, 2011.

OLARTE ENCABO, S.: Politicas de empleo y colectivos con especiales dificultades, Aranzadi, Cizur Menor, 2008.

PERONI, L. \& TIMMER A.: "Vulnerable groups: The promise of an emerging concept in European Human Rights Convention law", International Journal of Constitutional Law, vol. 11, no 4, 2013.

POQUET CATALÁ, R.: "De nuevo con la discriminación por razón de sexo en el empleo. Última doctrina judicial comunitaria”, Derecho de las Relaciones Laborales, no 2, 2019.

PRESNO LINERA, M.A. (coord.): Protección jurídica de las personas y grupos vulnerables, Procuradora General del Principado de Asturias, Oviedo, 2013.

RODRÍGUEZ ESCANCIANO, S. \& GÓMEZ GARCÍA, F.X.: "La edad como factor de vulnerabilidad social: algunos factores merecedores de preocupación", Derecho de las relaciones laborales, no 5, 2018.

RODRÍGUEZ-PIÑERO \& BRAVO-FERRER, M.: "Nuevas dimensiones de la igualdad: no discriminación y acción positiva", Persona y Derecho, no 44, 2001.

SANGUINETI RAYMOND, W.: "La edad: ¿cenicienta de las discriminaciones?”, Trabajo y Derecho, no 59, 2019.

SAN MARTÍN MAZZUCONI, C. (coord.): La politica de empleo como instrumento de inclusion social: un análisis jurídico, Dykinson, Madrid, 2019.

TRINIDAD NÚNEEZ, P.: "La evolución en la protección de la vulnerabilidad por el Derecho Internacional de los Derechos Humanos", Revista Española de Relaciones Internacionales, no 4, 2012.

VACA BUSTOS, L.: "Legislación y políticas públicas en España, respecto a la inmigración y su inserción en el mercado laboral”, Revista de Derecho de la UNED, no $25,2019$. 